\title{
Shuttle Program Loads Integration: Going From Concept to Operations and Staying Successful
}

\author{
Karen Bernstein ${ }^{\mathrm{i}}$ and George James ${ }^{\mathrm{ii}}$ \\ NASA/JSC Structural Engineering Division, Houston, TX 77058 \\ Alden Mackey ${ }^{\text {iii }}$ \\ Barrios Technology Inc., Houston, TX 77058 \\ Clarence Thomas Modlin ${ }^{\mathrm{iv}}$ \\ Dickinson, TX 77539 \\ Neill C. Murphy ${ }^{\mathrm{v}}$ \\ NASA/MSFC, Huntsville, AL 35812 \\ Steve Brolliar ${ }^{\mathrm{vi}}$ \\ Dynamic Concepts, Inc., Huntsville, AL 35806
}

\begin{abstract}
From the beginning of the Shuttle Program to its end, integrated loads and dynamics analyses and tests have been critical in shaping the vehicle design and operational decisions for NASA and its customers. Starting with scaled models and simple mathematical simulations of the structural dynamics, engineers defined the required structural stiffness and predicted the limit loads for each element of the system. Early structural tests provided reasonable confidence that the models and predictions were good. The first launch of the Space Shuttle brought surprises, though, when the ignition overpressure event caused a forward fuel tank support strut to buckle, among several unexpected effects. The launch pad and other ground equipment became an integral part of the system integration, especially where the acoustic and pressure environments of ignition and lift-off were concerned. Following the Challenger accident, operating limits were changed in response to new understandings of how the integrated system performed. Controlling loads while maximizing performance was a key tenet of the Performance Enhancement design process, which enabled construction of the International Space Station. During the return to flight after the Columbia accident, engineers grew to understand that loads during the roll maneuver were also important to the vehicle's structural margin and life. At this point the crawler transport from the Vehicle Assembly Building to the launch pad also became a part of the integrated loads analysis. Even in the last years of the Space Shuttle Program, new data still provided interesting insights into this complicated and fascinating spaceship. This paper will present some examples of the important findings by the team of specialists that supported the Integrated Loads and Dynamics Panel for the Space Shuttle Program.
\end{abstract}

\footnotetext{
i Space Shuttle Integrated Loads and Dynamics Panel Chair, NASA/JSC Structures Division, ES2, 2101 Nasa Parkway, AIAA member. Current job title: Commercial Spacecraft Structures System Lead.

ii Space Shuttle Integrated Loads and Dynamics Panel Chair Emeritus, NASA/JSC Structures Division, ES6, 2101 Nasa Parkway, AIAA member. Current job title: Orion Loads Panel Chair.

iii Space Shuttle Integrated Loads and Dynamics Panel Chair Emeritus. Current job title: Senior Systems Engineer, 16441 Space Center Blvd., Suite B-100.

${ }^{\text {iv }}$ Space Shuttle Integrated Loads and Dynamics Panel Chair Emeritus. 1216 Plantation Dr. AIAA Associate Fellow.

${ }^{v}$ Senior Aerospace Engineer, Propulsion Systems Dept., NASA/MSFC ER40.

${ }^{v i}$ Senior Engineer/Scientist, 6700 Odyssey Drive, Suite 202.
} 


\section{Program Beginnings}

Early in the development of the Space Shuttle, the Space Shuttle Program Office (SSP), also called Level II, chartered technical panels that allowed the elements of the National Space Transportation System (NSTS) to be integrated successfully. The panels covered technical areas such as integrated thermal, aerodynamics, loads and others. Each panel was led by NASA engineering and staffed by engineers from the various NASA centers and contractors responsible for parts of the NSTS. The panels began working at the start of the Shuttle Program, and operated continuously throughout the Program, solving problems large and small. This paper describes the evolution of the Shuttle Loads Panel, and some of the major engineering achievements of the Panel over the thirty years of the operational Shuttle Program.

The design and analysis work done during development of this unique space transportation system resulted in a spectacular thirty years of flights to and from low earth orbit, beginning with STS-1 in April, 1981. Those thirty years included two fatal accidents and 133 successful missions, buttressed by the day-to-day support of dedicated engineers and technicians. The Shuttle Loads Panel was an important part of that team, using a triage approach to set priorities and resolve many issues. Descriptions of early engineering challenges for the loads team are described in other papers (see Glynn ${ }^{1}$ and Mackey $^{2}$ ).

\section{STS-1 and the Orbital Flight Tests}

Data gathered during the first few missions confirmed the predictions made by the engineering test and analysis, with a few exceptions. These exceptions became assignments for the Level II Loads Panel: Solid Rocket Booster (SRB) ignition overpressure (IOP) analysis and mitigation, main engine ignition acoustics updates and unexpected lofting during the high $\mathrm{Q}$ boost are three of the many topics addressed by the Panel in the first few years of the Program.

\section{A. SRB IOP}

Before STS-1, the SRB IOP loads had been predicted based on tests using two Tomahawk rocket motors. The Tomahawk was employed as a $6.4 \%$ scale model of the SRB, and the pressure wave measured during its ground firing was scaled up and applied analytically to a numerical model of the stacked shuttle vehicle. During the first launch of the shuttle, the magnitude of the vehicle's response to the SRB IOP was significantly higher than predicted, resulting in damage to a structural support member at the forward end of the Orbiter. Needless to say, this was a frustrating finding. The Loads Panel along with propulsion systems experts had spent the previous five years examining the SRB IOP environment very thoroughly and had concluded that the vehicle would not be exposed to

damaging loads during this event. Program managers constrained the next launch of the shuttle to the successful mitigation of this hazardous condition.

After the flight, engineers went back to the data and determined that the $6.4 \%$ scale model tests conducted did not simulate the SRB ignition events well because of a time lag in the ignition of the two Tomahawk motors; the pressure wave from one arrived before the other, and the overpressure conditions in the test were subsequently lower than what was experienced by the Shuttle during STS-1. Additionally, the analysis of the IOP data was flawed with excessive "smoothing" which altered the basic characteristics of the IOP waves, and the structural loads model grid was too coarse to accurately calculate the generalized force time history of the pressure wave moving across the vehicle. The primary frequency content of the pressure wave was predicted to be $4 \mathrm{~Hz}$; the flight data showed it to center around $6 \mathrm{~Hz}$. Only the Orbiter exhibited a significant resonance to this wave, and certain Orbiter components were found to have reached $80 \%$ of their design limit load during the vibrations that resulted from the IOP. ${ }^{3}$

Some of the errors in achieving a good scaled replication of SRB ignition stemmed from the incorrect assumption that the source of the wave would be at the flame deflector. This was discovered when the Tomahawk test was repeated after STS-1, this time with better simulation of the boundary conditions present at launch. In this retest, a single Tomahawk was fired, with a large plate installed at the centerline of the vehicle to provide a reflection of the pressure wave. This eliminated any concerns with the timing of the ignition pulse for two motors. The initial source of IOP was determined to be near the nozzle exit plane (10 ft downstream of SRB nozzle), instead of the flame deflector (50 ft below nozzle) as was originally believed. For STS-2 and on, the basic frequency content and the magnitude of the IOP wave during the launch sequence were effectively reduced by adding water troughs over the SRB exhaust ducts, and improving the deluge system in the flame trenches to reduce the temperature of the exhaust plume. ${ }^{3,4}$ The dynamic model of the Orbiter used in analyzing the vehicle's internal loads during SRB IOP was 
modified to include 200 system modes so that the predicted response would be significantly more accurate than what was done prior to STS-1.

The SRB IOP problem illustrates an important point when working on complicated issues with limited time and resources. The people involved in solving a problem each have their own bias, and they influence their analysts and others, knowingly or not, in the direction of their bias. The group assembled to do the original work on the SRB IOP environment had been encouraged to simplify the environment description by smoothing the data, thereby easing analysis and speeding results. Additionally, prior to STS-1 the structures team was challenged by other integrated load events during ascent and did not consider the IOP issues as critical as those. After STS-1, the analysts noted that excessive smoothing of the $6.4 \%$ test data prior to STS-1 not only reduced the predicted amplitudes of the IOP, it also altered the predicted frequency characteristics of the IOP waves. Decisions about how to scale the data from the $6.4 \%$ model to full scale appear to have been made in part to minimize the magnitude of the predicted environment. Feedback from data users should be considered but should not be the basis of data modification.

The second launch of the Shuttle Program was held up until the IOP issues were resolved. The water system performed as intended for the remainder of the program, but measurements of the pressures and noise at launch were made each time, and whenever the water system had anomalies the data showed corresponding changes.

\section{B. Main Engine Ignition Acoustics}

The $6.4 \%$ simulation of the Shuttle launch environment was not used to predict the acoustic or overpressure environments on the vehicle from main engine ignition (MEI) as it was for the SRB IOP, because the subscale engines available for this test did not accurately replicate the SSME acoustics. Preflight predictions were based on engine acoustic prediction methods (semi empirical) and data taken during the preliminary flight certification tests using the Main Propulsion System Test Articles (MPTA). The Orbital Flight Tests (OFTs), otherwise known as STS-1 through STS-5, demonstrated that the reality was significantly different than predicted, and the acoustic environment had to be redefined. Following STS-5, the Loads Panel baselined a revised acoustic database for Shuttle launch by enveloping all of the data taken during the OFT launches. The acoustic data, taken by pressure sensors and microphones on the OV-102 (Columbia) vehicle, was processed with a fast Fourier transform routine using a 0.5 second window, which corresponded to the duration of maximum acoustic energy seen in the data, and $1 / 3$ octave bins. Analysis of the structural response to the acoustic environment was performed numerically, using zones defined for different parts of the Orbiter structure - the zones were defined using structural landmarks and engineering judgment. But since the instrumentation was scarce (only nine microphones were provided in the aft half of the Orbiter for this effort), each zone covered large segments of the structure.

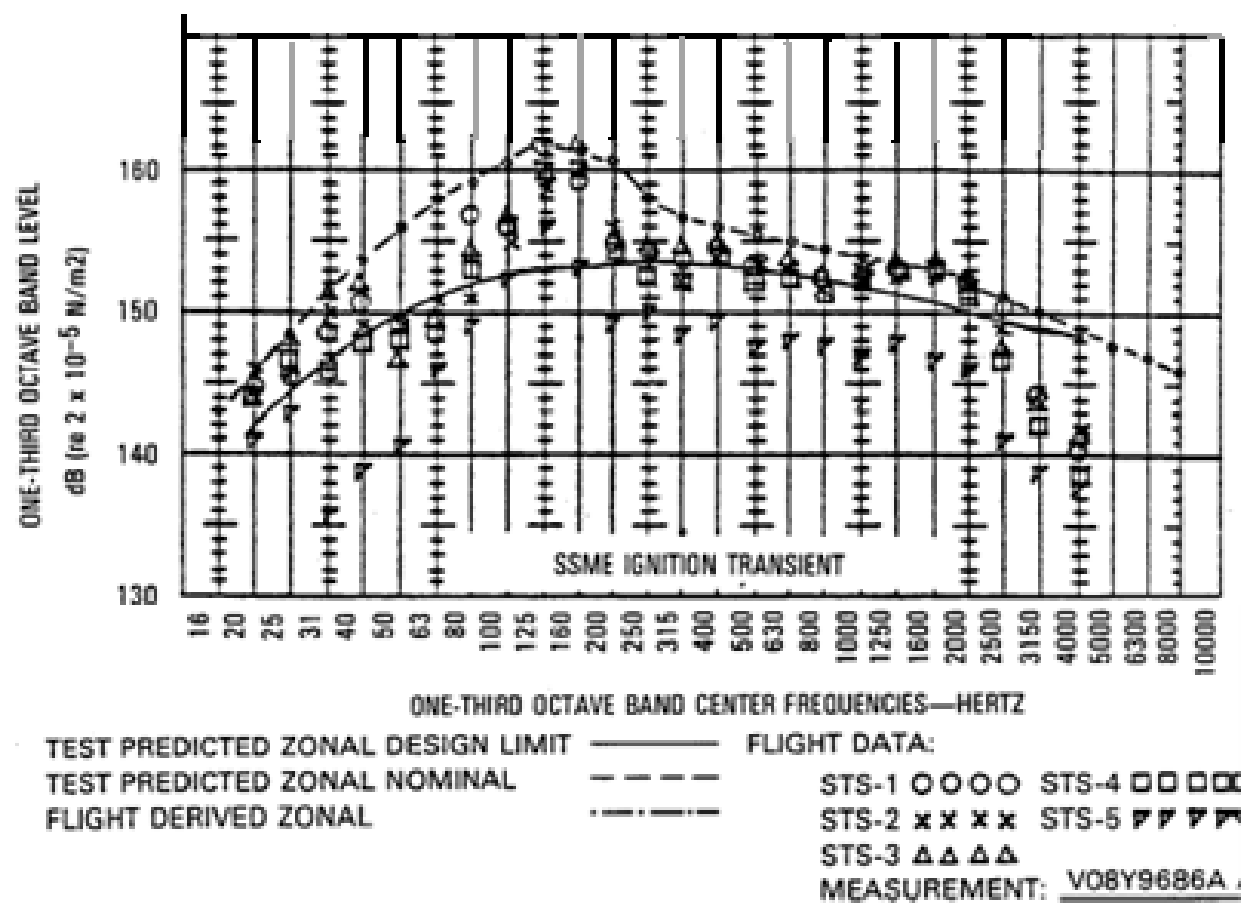

Figure 1. MEI Acoustic Environment at Base Heat Shield Center. 
The numerical analysis discussed above used analytic dynamic models built early in the Program and correlated to vibration test data taken in the original verification test programs. MEI acoustics can affect subsystem vibration environments, panel accelerations and structural fatigue life and they peak at the same time as MEI IOP and around 3.5 seconds before the SRB IOP. Following the post-OFT changes in the acoustic and shock data book environments, updated structural analysis of the acoustic environment resulted in fatigue life definitions that were well within the specifications for the Orbiter vehicle and did not identify any strength or life concerns for the required design life of 10 years or 100 missions.

\section{Unexpected Lofting}

Another issue that arose during STS-1, unexpected lofting during ascent, relates to how the aerodynamic performance of the shuttle was predicted pre-flight, vs. how the integrated vehicle actually flew. When the flight path diverged from the planned trajectory during high Q boost, the altitude of the vehicle at staging was higher than anticipated. While there were no significant negative consequences from this divergence, it was clear to the Integrated Loads and Aero Panels that an error had been made somewhere. The root cause turned out to be poor modeling of the flow around the External Tank (ET), Orbiter and SRBs and an incomplete understanding of base pressures due to engine plumes. ${ }^{5}$

The predicted altitude profile was based on wind tunnel test results which did not adequately simulate the engine plumes and thus the base pressures weren't predicted accurately. The wind tunnel testing had been done in three segments: subsonic to Mach 1, Mach 1 to Mach 1.55, and Mach 1.55 to the limit of the tunnel. The subsonic test data matched the computed aerodynamics very well, as did the higher mach testing. The Computational Fluid Dynamics (CFD) models and the midrange wind tunnel tests never achieved agreement as closely as the others. Hot plume simulations were performed after STS-1, and during the remaining Orbital Flight Test (OFT) missions, base and fore body pressures were measured to confirm the new test data. The trajectories were accurately predicted following this work.

\section{Integrated Aerodynamic Loads Issues}

The improved fore body predictions did not solve another issue - mismatch between predicted wing loads and measured wing strains during STS-1 and later flights. The preliminary design of the Orbiter vehicle was completed before the ET and SRB designs were begun, and before any integrated aerodynamic analysis was done. Once the tank and SRB configurations were being worked, designers added a structural cross beam to the ET aft attach point, which created a shock on the Orbiter wing that Orbiter designers had not anticipated in their preliminary design work. Such complicated integrated analyses and design challenges required the work of a Level II Loads Panel, which could direct analysis tasks for each element and report to the Program how the issue could be managed operationally, or whether additional budget would be needed for redesign or new tests.

Orbiter wing designers had planned to keep wing loads between $-1 \mathrm{~g}$ and $+2.5 \mathrm{~g}$ during entry, which was the critical design case for the wings before the integrated vehicle analysis showed otherwise. The shock at the cross beam during ascent directly affected the wing, and pushed the wing loads beyond $+2.5 \mathrm{~g}$ for this phase of flight. This mismatch between initial design conditions and the integrated vehicle analysis raised concerns about possible redesigns being required as the aerodynamic load data became more mature ${ }^{6}$. The Program implemented operational controls rather than a redesign of the integrated vehicle. The Orbiter ascent would be done with a more negative angle of attack than previously planned. The elevons would be moved through a load relief cycle during ascent. And a wing load calibration program was implemented later in the Program, which resolved all issues concerning the pressure distributions on the orbiter wings during ascent.

Following the successful completion of the OFT missions, NASA's Shuttle Program proceeded on with operational flights until the Challenger accident in January 1986.

\section{Post Challenger}

In response to the accident and the major reviews, redesigns and recertifications that were required to reestablish confidence in the engineering and processes used by the Program, all flights ceased for two and half years. This afforded the Shuttle Loads Panel an opportunity to catch up on issues that had remained open after the OFT 
missions. One of these was a problem with the loads in the SRB aft skirt, which turned out to be different than what was originally modeled when the Shuttle structural analysts considered the pre-launch and launch conditions. The problem-solving approach used by the Loads Panel also illustrates the use of load indicators, an important tool for the structural analyst working on a complicated system like the Shuttle.

\section{A. SRB Aft Skirt Weld Failure}

The aft skirts of the SRBs are the supports for the entire shuttle stack on the Mobile Launch Platform (MLP) (see Figure 2). These welded up conical structures attach to the pad at four points each, where frangible bolts hold the stack down until the moment when SRB ignition begins. But launch is not the only design condition for the skirts. The different flight regimes where the SRB skirts see different types of loading during different phases - rollout, prelaunch, liftoff, and ascent. To efficiently find the maximum design load for the skirts and other specific structural elements, analysts commonly develop combined load case analyses, which they can then sort to find the critical conditions. The Shuttle Program took this concept and created a special analytical tool, a meta-stress or meta-load which is used to identify cases that must be examined more closely to make sure the applied loads aren't exceeding the part's capability.

Load indicators are what the Shuttle Program called these tools, which were used to search through the integrated simulation results to identify the critical load cases and time slices for recovering the requested design loads data. In defining the variables used in a load indicator equation, each SSP element identifies the critical locations on their hardware. The SSP element then creates the indicator that is provided to Level-II Systems Engineering \& Integration personnel for the purpose of selecting a design load case and time slice that will maximize or minimize the indicator. These indicators are based on structural tests or analyses. The indicator can be a load or combination of loads, an acceleration, calculation of a stress at a location, or a displacement. The only requirement is that the indicator be based on information available from the simulation. Initially all of the SRB indicators were based on a load or combination of loads. The indicators are used during design verification, mission planning and day-of-launch assessments of weather and other flight variables.

Well into the operational life of the Shuttle Program a load indicator was created specifically to address a strength concern in the SRB aft skirt weld. An SRB aft skirt structural test identified the aft skirt forging-to-skin weld as the most critical area on the aft skirt. In 1986, this weld failed during a structural qualification test (STA2B) for a new composite motorcase, at $128 \%$ of the specified design load. The location of the weld that failed is shown in Figure 3. The SRB aft skirt that failed was a part of the test fixture and not part of the hardware being qualified.

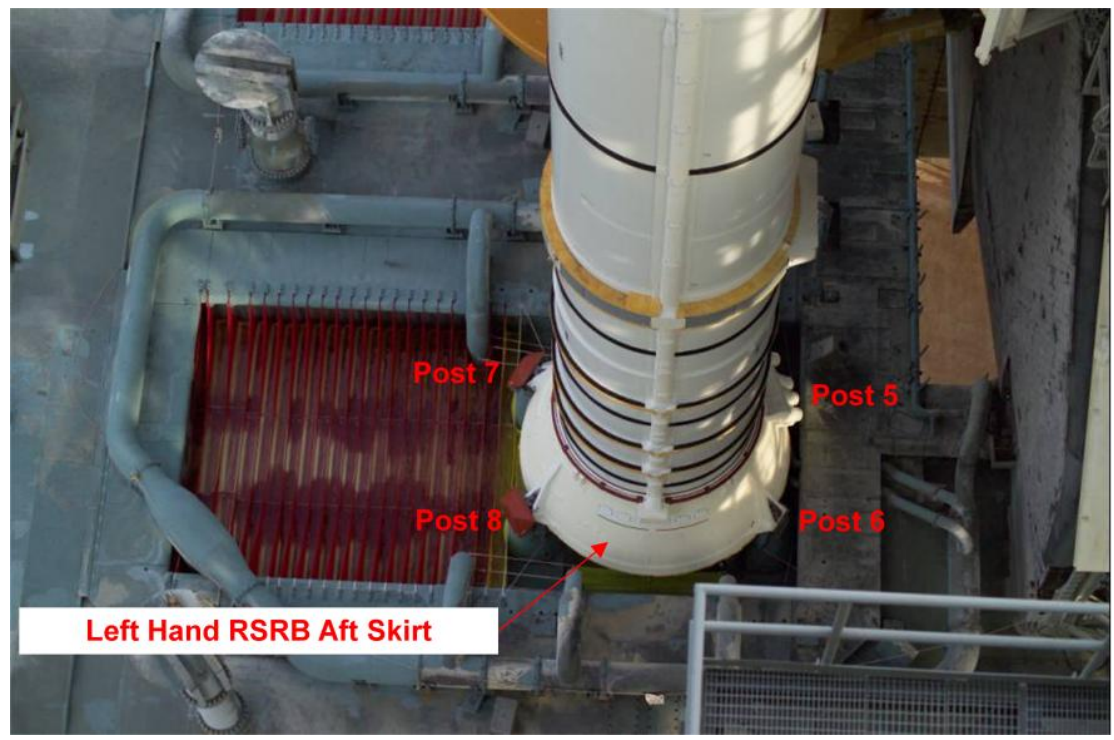

Figure 2. View of SRB Aft Skirt. 


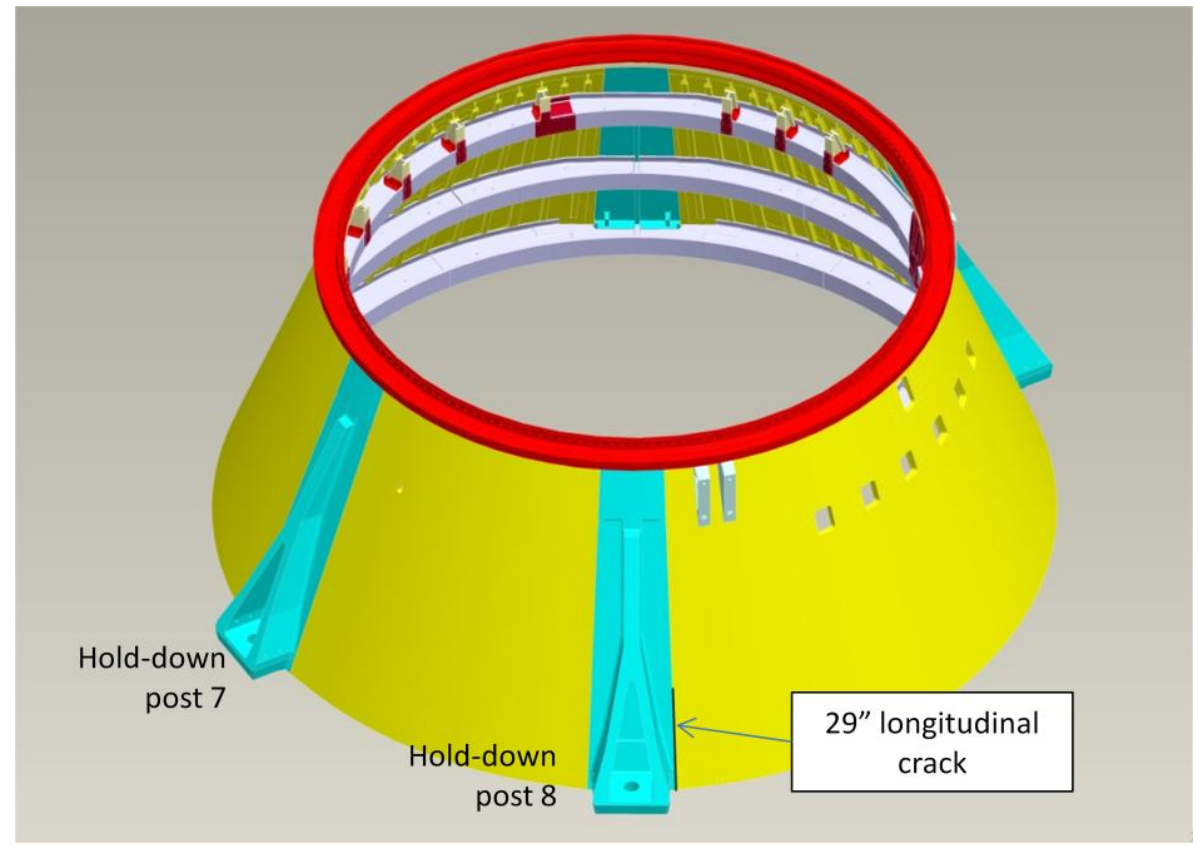

Figure 3. STA-2B Aft Skirt Weld Failure.

At the time of the weld failure, the only indicators used to select design load cases for the aft skirt were the maximum axial compression and tension $\left( \pm \mathrm{F}_{\mathrm{X}}\right)$ at each hold-down post (HDP). The first aft skirt structural test, designated STA-1, was completed without a failure in October 1979. As shown in Table 1 for STA-1, the maximum axial compression load was 1435.7 kips at HDP 7, or approximately 1.4. x 1000 kips limit load. The failure during STA-2B occurred at a maximum axial compression load with approximately the same value as used in STA-1.

A third structural test, designated STA-3, was conducted in March 1988 after implementation of an internal structural modification designed to strengthen the weld. The aft skirt weld again failed at post 8 , at $129 \%$ of the design loads despite the modification. The failure was not expected because the maximum axial compression at that post was only 1294 kips, $10 \%$ lower than the previous tests. A new indicator equation was defined: the critical weld stress intensity (CWSI). This indicator had a value of $62.5 \mathrm{ksi}$ calculated after the STA-3 test, $20 \%$ higher than the CWSI calculated for STA-1, indicating why the weld failed.

The major lesson learned from this structural test failure was that the stress in the critical weld is a function of all of the forces (FR, FT, FX) at each of the four HDPs (twelve components) and not just the maximum or minimum axial load. The CWSI uses influence coefficients from test data and finite element models to relate the radial, tangential, and axial loads at all four hold-down posts to the stress in the critical weld. See Equation (1), the load indicator equation for the SRB CWSI.

$$
\begin{aligned}
& (0.96 R+0.18 T-0.65 A)_{P O S T 5}+(1.05 R-1.01 T-0.42 A)_{P O S T 6}+(-4.20 R-1.20 T+1.90 A)_{P O S T 7}+ \\
& (26.7 R+9.00 T-11.0 A)_{P O S T 8}=C W S I
\end{aligned}
$$

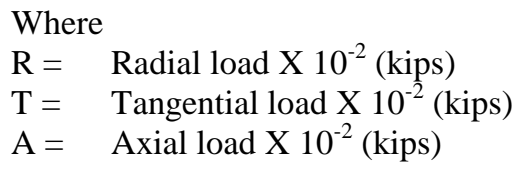


Table 1. Post Loads and Critical Weld Stress Intensities.

\begin{tabular}{|cc|c|c|c|}
\hline \multicolumn{5}{c}{ STA-1 @ 100\% Load } \\
\multirow{3}{*}{ Fx } & POST 5 & POST 6 & POST 7 & POST 8 \\
\cline { 2 - 5 } Fr & 575.4 & 637.1 & -1435.7 & -1296.4 \\
Ft & 52.1 & 40.7 & -403.6 & -361.4 \\
CWSI & -195 & 285.7 & -181.4 & 251.4 \\
\cline { 2 - 5 } & $\mathbf{- 5 1}$ & $\mathbf{- 6 8 . 5}$ & $\mathbf{5 1 . 9}$ & $\mathbf{5 1 . 9}$ \\
\hline
\end{tabular}

STA is Static Test Article

All loads are in KIPs

Sign Convention:

Fx axial tension is positive

Fr Radially outward is positive

\begin{tabular}{|cc|c|c|c|}
\hline \multicolumn{5}{c|}{ STA-2B @ 100\% Load } \\
\hline \multirow{5}{*}{ Fx } & POST 5 & POST 6 & POST 7 & POST 8 \\
\cline { 2 - 5 } Fr & 569.8 & 579.1 & -1395.3 & -1440.3 \\
Ft & 30.2 & 92.3 & -320.9 & -312.4 \\
CWSI & -215.5 & 314.7 & -87.6 & 154.3 \\
\cline { 2 - 5 } & $\mathbf{- 6 0 . 6}$ & $\mathbf{- 4 9 . 9}$ & $\mathbf{5 5 . 6}$ & $\mathbf{6 8 . 5}$ \\
\hline
\end{tabular}

$\mathrm{Ft}$ Tangentially clockwise is positive

\begin{tabular}{|cc|c|c|c|}
\hline \multicolumn{5}{c|}{ STA-3 @ 100\% Load } \\
\hline \multirow{3}{*}{ Fx } & POST 5 & POST 6 & POST 7 & POST 8 \\
\cline { 2 - 5 } Fr & 457.1 & 602.1 & -1456.6 & -1294 \\
Ft & -11.7 & 39.2 & -351.7 & -283.4 \\
CWSI & -136.5 & 225.1 & -140.6 & 164.1 \\
\cline { 2 - 5 } & $\mathbf{- 4 8 . 8}$ & $\mathbf{- 5 8}$ & $\mathbf{6 0 . 9}$ & $\mathbf{6 2 . 5}$ \\
\hline
\end{tabular}

The CWSIs for STA-1 and STA-2B are shown in Table 1. Given that the allowable stress for this weld was $48.1 \mathrm{ksi}$ it is clear that the STA-2B loading condition at post 8 would lead to failure. As shown in Table 1 for STA-1, the maximum axial compression load was 1435.7 kips at HDP 7, with a CWSI value of $51.9 \mathrm{ksi}$, about $7 \%$ higher than the allowable stress. During STA-2B, the CWSI value at post 8 , again calculated after the test, was $68.5 \mathrm{ksi}$.

The Aft Skirt flew with a waiver against the $140 \%$ factor of safety requirement from return to flight in 1988 until 1998 when an external bracket was designed and implemented to reduce the weld stress. The CWSI was used to protect the weld area while additional design solutions were sought. The CWSI indicator allowed Level II to search the load cases to find the worst combination of any hold-down post loads that would maximize the weld stress.

These test failures illustrate the importance of accurate and comprehensive load indicators so that Level II loads personnel can provide load cases to the elements that maximize stress in critical structural areas. The load indicators can also be an important tool for the system engineering and integration team to use to set maximum allowable limits that protect certification during future operational load cycles. Load indicators were used on every element, and on every major structural component of the Space Shuttle.

\section{B. Drag Chute Door Failure}

Two and a half years after the Challenger accident, when flights resumed with STS-26, the Program began taking data again from reactivated instruments on OV-102 (Columbia) and new instruments on OV-103 (Discovery). This decision conformed to the Program's renewed attention to the unknowns that still remained in understanding how the Space Shuttle Vehicle responded to its unique launch and ascent environments. The new acoustic data made clear that the environment update done after STS-5 might have enveloped the data from those first five flights, but did not envelope the environment completely, especially in certain zones of energy between $20 \mathrm{and} 40 \mathrm{~Hz}$, and $60 \mathrm{~Hz}$ to $160 \mathrm{~Hz}$. The change in the data was noted by the Loads Panel, but in the absence of any perceived risk to the vehicle no investigation was opened.

Engineers became more concerned about the disconnect between the post-flight data and the environments specified in the data book after STS-95, when the drag chute door fell off the aft end of the Orbiter during launch on 
October 19, 1998. A drag chute had been added to the Orbiter vehicle after STS-26 to address concerns about landing, and the door for the new compartment was designed to meet the environments specified in the data book. Failure analysis of the damaged door and attach hardware showed that the pins fractured due to overload, not fatigue. What had caused an overload of the pins during launch? The list of possible root causes included that the MEI environment may have exceeded the environment for which the aluminum shear pins were designed, the MEI environment was significantly different from previous flights, the door response during MEI acoustics may have been larger than what was observed during qualification vibration testing of the new door, the pressure component of the environment was not accounted for during the initial design, and that hydrogen detonation or fast burning may have caused a localized pressure environment excursion. The immediate solution after STS-95 was to replace the aluminum attach pins with inconel pins of much higher

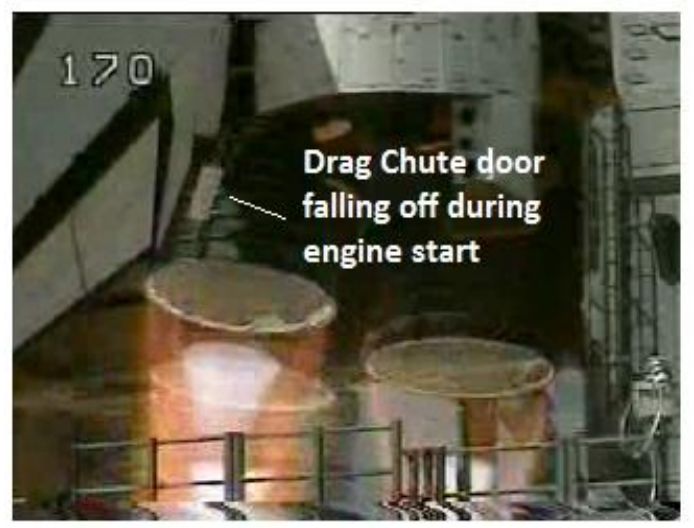

Figure 4. Screen Capture of STS-95 Launch. strength, and to add instrumentation to the door to directly measure the environments at this location. The Panel began longer term assessment to more fully understand the loads on the door during main engine start.

The drag chute door accelerometer and pressure transducer data from flights following STS-95 confirmed that the root cause of the STS-95 failure was engineers' poor understanding of the acoustic energy being experienced at this location, and the resulting selection of pins that were not strong enough to withstand the loads on the door. The Loads Panel became even more focused on getting a good handle on the pressure and acoustic environments at main engine start-up and SRB ignition. Before this work was completed however, another accident required the Panel's full attention.

\section{Post Columbia}

The last flight of OV-102 Columbia ended on Feb. 1, 2003. The stand down after the loss of STS-107 provided another opportunity to work off some additional unresolved integrated loads issues. There were at least three major issues that were worked out and resolved between STS-107 and Program termination in 2011: Roll-Out Loads, Roll Maneuver Loads, and MEI/IOP Loads (as well as a host of other less labor-intensive loads issues). None of these integrated loads issues were unknown to the Space Shuttle technical community but were issues that were longer term (i.e. fatigue vs. limit load), manifested only after some flight experience, or tied to hardware/operational changes to the system. Hence, it was a good risk trade to not work these issues extensively during the original design and operations phases of the Space Transportation System (STS). However, there was no good technical or risk reason to wait for the last quarter of the Program to fully understand and work these problems.

\section{A. Roll-Out Loads}

The roll-out to the pad is a slow process that takes several hours at the typical drive speeds of around 0.8 to 0.9 mph. In 1979, an initial rollout to the pad was performed with a representive Space Shuttle stack ${ }^{7}$. Based on this early data, the rollout was considered a relatively benign environment. In 1986, measurements were taken to determine strains in the SRBs during the rollout to the $\mathrm{pad}^{8}$. These measurements did not alter the logic that the rollout loads were generally ignorable. However, as the System aged and more emphasis was placed on understanding the vehicle's fatigue characteristics, this assumption became a subject for validation. While this assumption was being discussed by the Panel, a question was asked in 1999 about the loads produced by winds during rollout (in the context of extreme weather like thunderstorms and tropical systems). This resulted in a limited amount of instrumentation being placed on the Mobile Launch Platform (MLP) during a few rollouts. This data was then used to drive a fatigue analysis that was completed in 2003. This analysis cleared the wind loading questions but unexpectedly produced some very low fatigue life in certain Orbiter components. Therefore, work began in earnest to understand and properly analyze the rollout loading effects on the vehicle.

In November 2003, a team of engineers from four NASA centers and several contractor organizations performed a significant "Partial Stack Test." This test utilized a pair of SRBs and an ET crossbeam on an MLP and CrawlerTransporter (CT) to obtain operating data. This stack was rolled out at various speeds and surface conditions to obtain a significant set of engineering data. This configuration reproduced most of the mass of the full stack but 
could not reproduce all of the dynamics (the whole stack weighs approximately $12,000,000 \mathrm{lb}$ at rollout; the Orbiter and ET only account for about $310,000 \mathrm{lb}$ ). As the technical community began to study this environment, the rollout forcing function was found to contain a fairly rich spectrum with multiple narrow-band excitation forces. This creates a situation where individual modes of the vehicle can be driven into resonance and significantly increase structural response. This testing was followed in 2005 with instrumented rollout tests of the MLP and the CT. Later in 2006, the STS-115 stack was rolled to the pad with instrumentation on the Orbiter, the SRBs, the MLP, and the $\mathrm{CT}^{9}$. This data was used to generate forcing function estimates ${ }^{10}$ to clearly understand the situation and fatigue spectra to fully analyze the long-term effects on the Space Shuttle vehicle 9 . The final analysis to show that the Space Shuttle Vehicle had sufficient fatigue life with rollout effects included was presented in the spring of 2009. This ended the active work on the rollout problem but made everyone in the technical community aware that low level loads that operate over long periods of time do need to be fully assessed and controlled.

\section{B. Certification of the Roll Maneuver}

The roll maneuver involves the rotation of the Shuttle stack during ascent, shortly after clearing the launch pad, to the proper orientation for the final orbital inclination. This maneuver occurs at very slow velocities (Mach 0.2 to 0.5 ) and the resulting loads are intuitively low. Therefore, the initial integrated loads analyses did not include an evaluation of the roll maneuver. In early 2003, after the STS-107 accident, vehicle loads for the entire STS-107 ascent were reconstructed. The results of this reconstruction showed that the SRB aft interface load was exceeding one of the certification redlines for the Lightweight ET configuration. The Lightweight ET was used on STS-107 and would not be used again, but the replacement configuration using the Super Lightweight ET had similar redlines - the STS-107 reconstructed loads were within 5\% of the certified limit load for the new integrated vehicle.

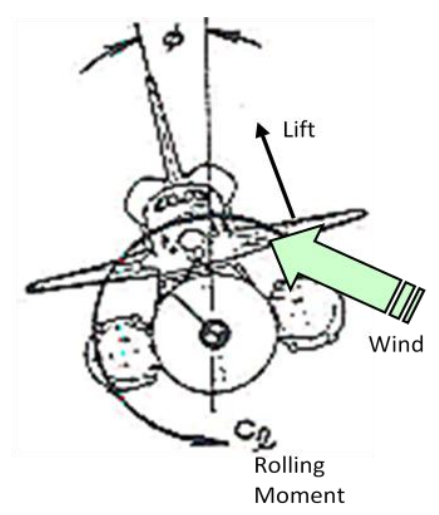

Figure 5. Roll Maneuver Variables.

Roll Maneuver Loads needed further assessment. It was found that the pitch gimballing of the SRB motors put a large up and down (Z) load on the SRB which is reacted by the aft attach struts between the SRB and the ET. The evaluation of the strut loading led to an evaluation of the loading on the other Shuttle elements. The Orbiter showed sensitivity to the roll maneuver, especially the wings and vertical tail as they interact with the winds and aerodynamic forces. This new information initiated a multi-year effort to fully understand this highly integrated loading event. 


\section{P13 Load Maximizes During Roll Termination}

SLWT February Dispersed Reconstructed Load Envelope (P13) Versus Time

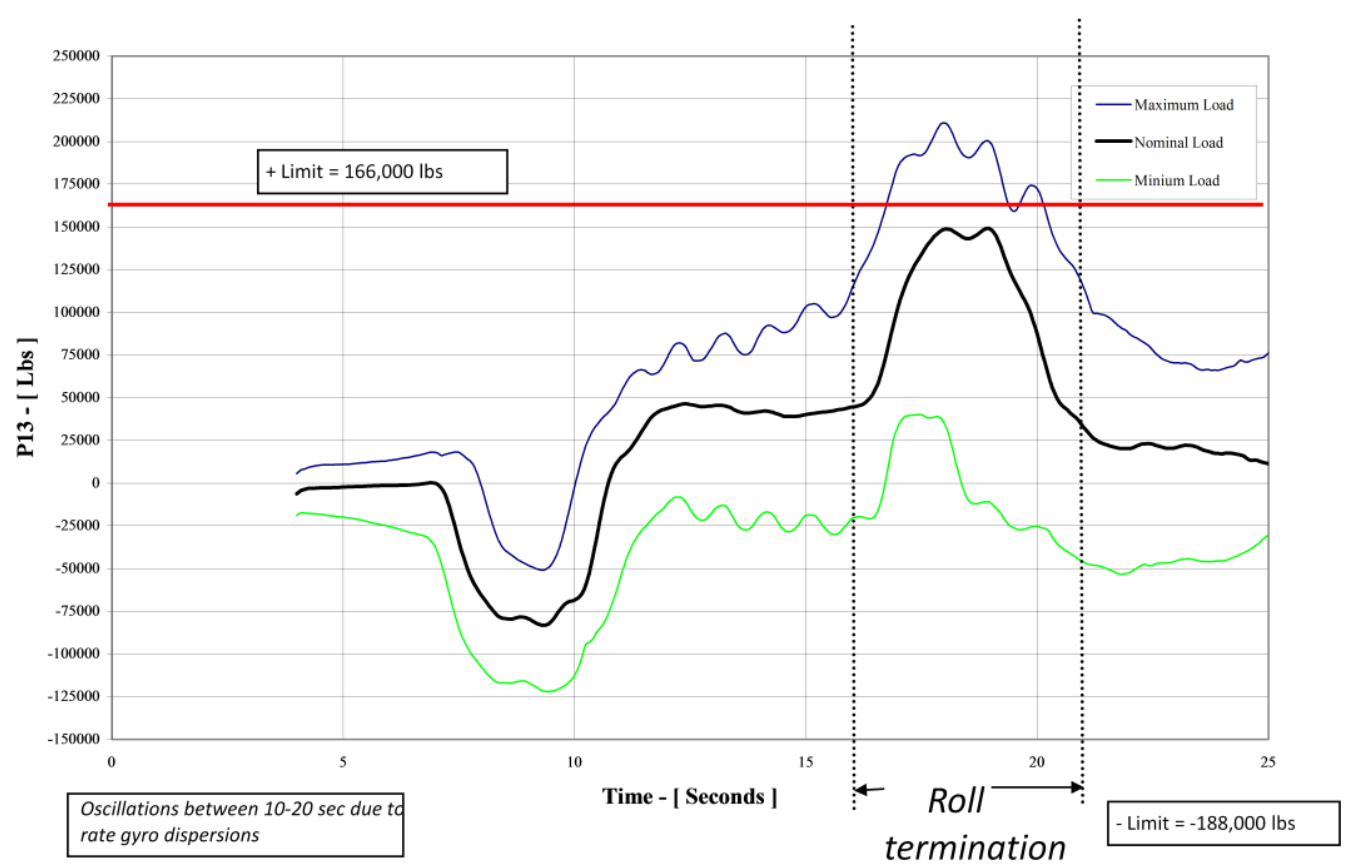

Figure 6. Load Indicator P13 time history for Ascent.

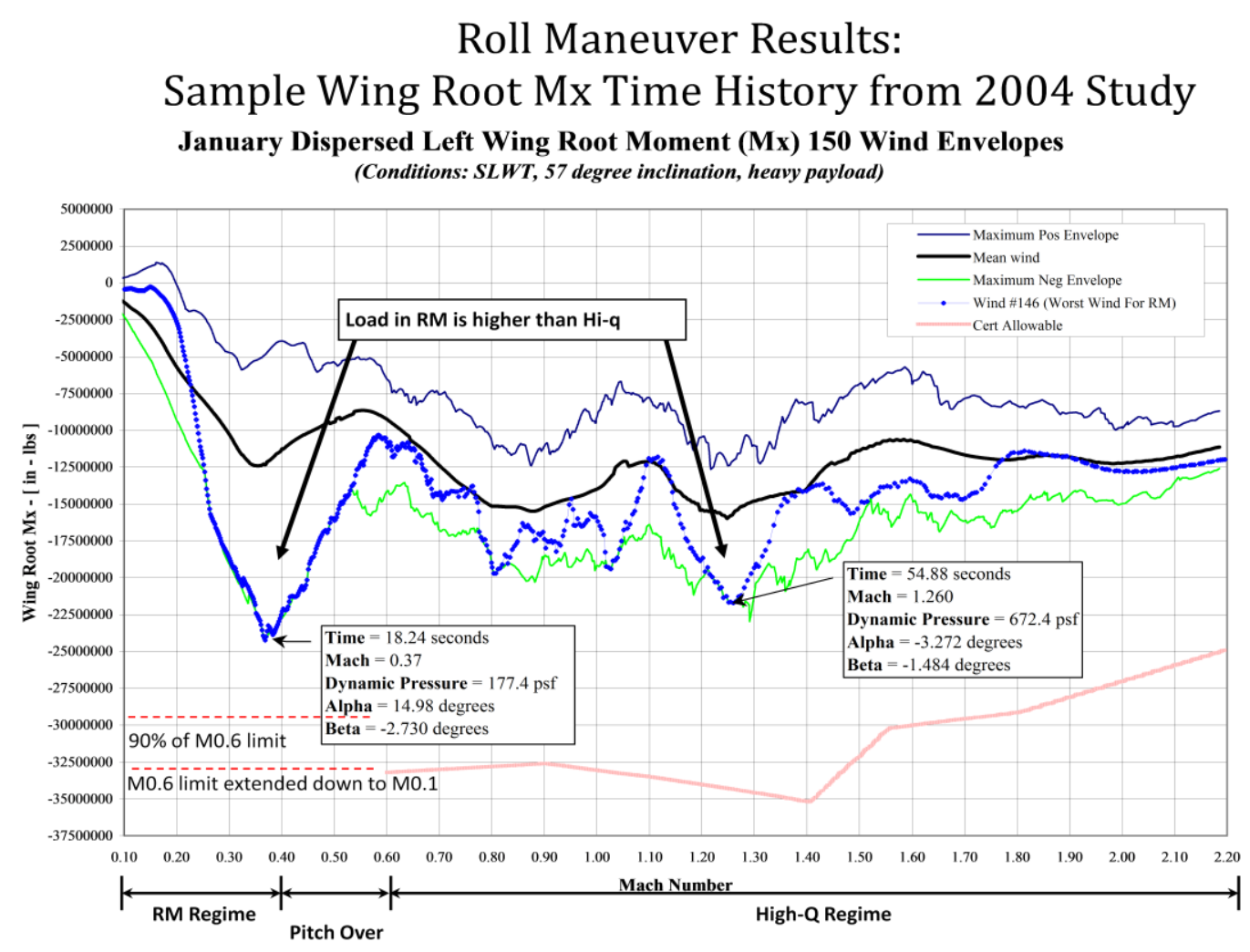

Figure 7. Wing Root Moment.

10

American Institute of Aeronautics and Astronautics 
During the summer and fall of 2003, the loads community developed an analysis plan, examined previous flight data (STS-26, -27, and -29 had instrumented struts), determined wind variations in this flight regime, and developed an understanding of the deficiencies in the aerodynamics database. In the first quarter of calendar year 2004, the loads community began interacting with several other technical disciplines to address the Roll Maneuver issue including the Aero sciences (Aero) Panel; the Guidance, Navigation, and Control (GNC) Panel; the Natural Environments Panel; and the Day of Launch (DOL) communities. The technical panel members understood that the roll maneuver was flown differently after Performance Enhancement (PE) became the standard trajectory design, because the main engines were then configured for a parallel burn. The PE missions provided increased performance over previously used trajectories, but the changes also increased the strut loads. Ultimately, the SRB loads were not found to be wind sensitive, but the Orbiter loads were.

A troubling discrepancy was found between the existing wind tunnel data and the CFD results that were used to develop wind loads at 19 degrees angle-of-attack (beyond stall).. Note that the communities' work was based on this new CFD-based Roll Maneuver Aerodynamics Database (called RMAD). The Shuttle Program decided that Roll Maneuver would be subjected to an official recertification by this multi-disciplinary NASA-Contractor team. The spring and summer of 2004 were spent understanding the full extent of the issues by looking at more detailed Orbiter, SRB, and ET structures. Also, the cross-discipline analysis procedures were put in place. These elements provided the indicators and redlines that would be used to assess the integrated roll maneuver loads analyses. The first load sets became available in December of 2004. Also, since the aerodynamic loads were to be CFD-based, the communities began to struggle with the discrepancy beyond 19 degrees angle-of-attack.

Calendar year 2005 saw a major effort to work the roll maneuver problem. Several joint and individual Panel meetings throughout the year involving the technical discipline panels listed above were held to deal with several highly integrated issues involving roll maneuver. The earliest conversations involved replacing the CFD-based Orbiter aerodynamic loads in RMAD with data from a recent wind tunnel test (denoted as IA-700). The idea was to resolve the discrepancy beyond 19 degrees. However, due to the need to prepare for the upcoming STS-114 mission, it was decided to work with RMAD but put in operational constraints to not launch if the winds would cause an Orbiter angle-of-attack of greater than 19 degrees during Roll maneuver. Besides the winds constraint, other issues worked by this team in 2005 and early 2006 included the development of Roll Maneuver Q-Planes (a set of trajectory constraint planes to protect structural limits), a new wind persistence approach for RM, uncertainties for RMAD, Day-of-Launch constraints implementation, transition aerodynamics (pad to start of Roll maneuver region), balanced load cases for all elements including cargo, launch probability, fatigue life ground rules, coverage of engine-out cases, wing buffet loads, and component loads (Orbiter windows, ET/Orbiter interface mechanisms, payload bay cameras, etc.). STS-114, STS-121, and STS-115 all flew with this same basic set of information and using the same processes.

In the spring of 2006, the community rolled out RMAD2. This upgraded aerodynamics database used the wind tunnel data mentioned above to relieve the 19 degree discrepancy. The effort hit a snag in the summer of 2006 as decades-old discrepancy was found in the ascent loads codes. The input coordinate that defines the aft SRB/ET separation plane was not defined correctly in some codes. Updating the coordinate generated additional load indicator exceedances in the SRB and the ET. Balanced load cases to generically clear these exceedances were put off for some time as code updates and re-runs had to be performed. In fact STS-117 and STS-118 were flown with the incorrect coordinates driving some of the calculations for a limited number of indicators. A series of discussions were held to upgrade the buffet increment based on the IA-700 wind tunnel data. In the end the community accepted RMAD2 with higher loads past wing stall (the 19 degree boundary) as well as higher buffet loads. In early 2007, balanced load cases began to be released to the elements with these increased loads. Analysts for the Orbiter Project received the RMAD2 load cases in spring of 2007 but SRB analysts did not receive RMAD2 load cases until fall of 2008.

All Roll Maneuver certification work was done to support ISS missions to an Orbital inclination of 51.6 degrees. However, the STS-125 mission to the Hubble Space Telescope was eventually approved to an inclination of 28 degrees. Hence a significant effort in the last half of 2007 and throughout 2008 involved updating or clearing all RM products for a 28 degree inclination Hubble mission. The final piece of RM work finished in May of 2009 and involved the delivery and assessment of Orbiter fatigue loads. The STS-125 Hubble mission and the STS-127 mission to ISS, in May and July of 2009, were the first missions to fly with no outstanding Roll Maneuver issues. 
As the Loads Panel dealt with the roll maneuver issue several missions had to fly with mission-specific certification, additional launch constraints, or some additional but acceptable risk. In the end, the Shuttle Program was able to remove all of those constraints except for the fully certified and generic Q-plane constraints needed to safely take the vehicle through the low-energy but highly loaded Roll Maneuver flight regime. To reach that point, the Loads community worked as part of a much larger and multi-discipline integration team to fully understand and certify an intricate flight maneuver. Although the original designers were probably correct in downplaying the Roll Maneuver loads to focus on higher-energy events, the community failed to continue to monitor the lower level events (such as Roll Maneuver) as the Program unfolded. Any maneuver a launch vehicle executes during its ascent should be evaluated and included in the limit load and fatigue load set for transmission to the vehicle element for design assessment, especially after operational or configuration changes.

\section{MEI/IOP Data Review, Instrumentation Recalibration, Environment Update}

The STS-107 fault tree included branches for exceedances of MEI acoustic energy and the SSME ignition overpressure loads. While the MEI acoustics for STS-107 were outside the data book limits like many of the previous Shuttle missions, the Loads Panel quickly established that this was not a cause of the fatal accident that ended this mission. Attention to the acoustic environment at this time provided an opportunity to improve the database and better understand the vibration environment due to the MEI, and whether our fatigue analysis had been conservative.

In May 2004, the Panel reviewed sensitivity studies about the data reduction methodology, and decided to change the way the acoustic data was analyzed. Where the original work had used a 0.5 second Hanning window for the data reduction from instrument output of psi vs. time to decibels vs. frequency, it now seemed reasonable to widen that window to 2 seconds. The main engine ignition occurs over a 2 second time span, as demonstrated in the figure below. Additionally, from a structural engineering point of view, a load occurring over half of a second hardly seems long enough to elicit a structural response. After significant discussion, the Panel agreed that averaging the data over this 2 second window was appropriate.

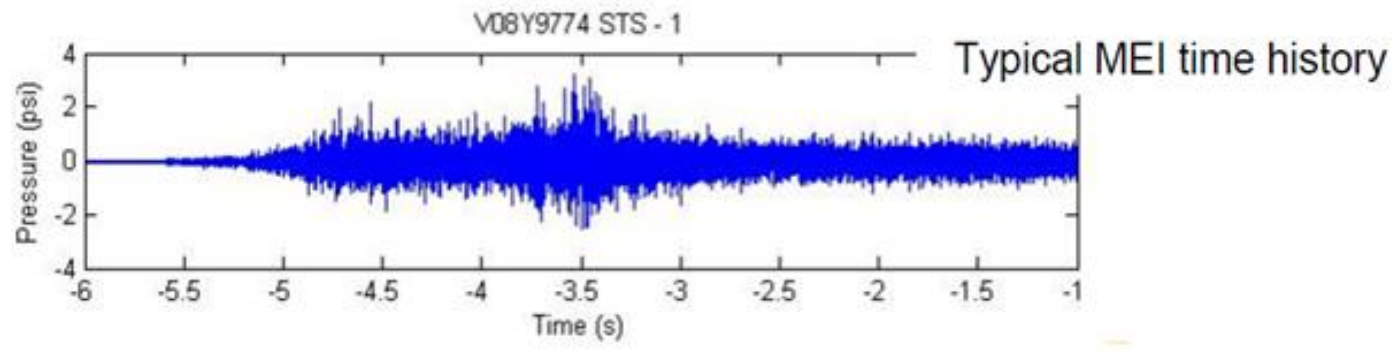

Figure 8. Typical Acoustic Data at Base Heat Shield Center.

At this time the Loads Panel also recommended that OV-105 be outfitted with instruments to measure the acoustic and pressure environments at MEI and launch, and that disconnected instruments on OV-103 be reactivated. This would enable the Panel to examine more data for environments that were proving hard to predict from early tests and flights. This effort was approved in November 2004, and took place over approximately 20 months.

Finally the new data started coming into the Panel. As the Panel reviewed the acoustic and pressure post flight data, theories were proposed as to why the acoustic energy in particular had gotten so far outside the original limits. The Panel noted that the main engines had been through a block update in the late '90s, and the propulsion system experts began trying to link the changes in the acoustics to the changes in the engines. The post-processing change in the window duration made comparisons difficult, and in 2008 analysts went back to the source data and recalculated the environments using the original half second window and reviewed the environment differences again. Analysts had also gathered enough engine firing data to demonstrate that main engine block updates were not the source of any change in the acoustics at start-up. 
It also became clear at this point that while the data reduction window had been widened from 0.5 seconds to 2.0 seconds, the fatigue analysis had not been corrected to reflect the different duration of the applied sound pressure levels in the structural models. Additionally, widening the window seemed to effectively blunt the extremes by averaging the acoustic data over a longer duration, and resulted in a lower overall environment. The Panel debated the merits of using a window that made sense from the structures point of view, versus attempting to capture a conservative estimate of the acoustic environment to minimize the likelihood of a structural failure due to fatigue from this environment. Accelerometer data from certain parts of the vehicle were found and showed that the structure was in fact responding to short duration events.

In 2008, the Orbiter Project structures team reported to the Panel that their preliminary assessment of the updated MEI environment, using the 0.5 second window, resulted in a few parts where strength and life margins were extremely low. The Orbiter structures team was asked to provide a detailed summary of the fatigue analysis and tile margin issues. Faced with an environment the Panel couldn't explain, potential structural strength and life issues and data that were consistent in its deviation from the original predictions, the Panel began to investigate the integrity of the data itself.

All of the instruments on OV-105 were new, as were several on OV-103, so it seemed that measurements from these instruments would be accurate. In discussing this, the Panel learned that none of the instruments were regularly calibrated. In fact, they hadn't been calibrated at all after each had been installed. Calibration plans require dedicated time from the ground crew. Since the Program had not used the instruments to define environments after the OFT flights concluded, no budget or schedule had been requested or allocated for a regular calibration effort. Now, however, the Panel did intend to use the data to make engineering assessments, and the fact that the instruments were not calibrated made the data inappropriate for engineering decisions. The Panel requested an effort to calibrate all the available instruments, those on the vehicles and even those that had been removed from the vehicles, and it took more than a year to get this done. As each instrument's calibration came in, analysts working on the problem were able to confirm that, with a few changes for calibration correction factors, the acoustic environment that the Panel was concerned about had been recorded correctly and the data book environments did not envelope the flight data.

Along with the debate about the window duration and data calibration, the Panel also reopened the discussion of ground rules that would identify which data would create the need for updating the environment. During this time period, the Shuttle Program had launches every two or three months, and the Panel was seeing a lot of post-flight data that exceeded earlier flights. In June 2009, the Panel established these ground rules:

- Run a root-mean-square of the pressure time history with a 0.05 second step and a 0.5 second window to find the highest value window for final processing.

- Use two $4 \mathrm{~Hz}$ bandwidth fast Fourier transforms with no overlap to create a power spectrum.

- Convert power spectra into $1 / 3$ octave decibels bands from 20 to $2000 \mathrm{~Hz}$.

- If new environment exceeds previous design limit by more than $3 \mathrm{~dB}$ within one of the $1 / 3$ octave bins, and is not a singular deviation, then $\mathrm{dB}$ level for that frequency would be increased in the design limit. The delta $\mathrm{dB}$ for the increase is rounded to the nearest integer.

- Existing design limit data above post-flight data will not be lowered.

Correlating the acoustic data with Marshall Space Flight Center analysis of the main engine ignition, including unsteady computational fluid dynamics modeling, the source of the peak MEI acoustics was determined to be the separation of the lip restricted shock and its oscillation of the SSME nozzle during the start transient. Identifying this source helped the Panel understand more about how the environment was being measured, and how placement of the instruments (and vehicle components) could result in shadowing from certain parts of the acoustic environment. This part of the discussion became important when the Panel had to determine how to apply data from a few instruments to the large structural areas of the vehicle that were being assessed.

In October 2009, the Orbiter Project structures team finished their analysis of the updated SSME IOP and MEI environments, which included increases in sound pressure levels for the base heat shield (BHS), the Orbital Maneuvering System (OMS) Reaction Control System (RCS), the vertical tail, the inboard elevon, the body flap and the upper fuselage aft of $\mathrm{X}_{\mathrm{O}} 940$. This analysis identified the OMS RCS stinger attach point and an access panel as low life parts, and found several tiles on the RCS that needed minor modifications to maintain a positive margin of safety for strength. 
In the discussion that followed, Orbiter Project structural engineers recalled that an OMS RCS access panel had in fact cracked during Shuttle operations in the ' $90 \mathrm{~s}$, which was discovered in 2000 during a maintenance down-time for OV-102 (see Figure 9). Following this problem report, all of the access doors on each vehicle were modified to strengthen this corner flange in response to the OV-102 damage. During that rework, no other damaged doors were found and an assumed pre-existing flaw on the OV-102 door was identified as the probable root cause of the crack. Detailed analysis of the modified door for the newest loads in 2009 showed that the part life was sufficient for the remaining flights of the Shuttle Program. Reviewing this history reminded the Panel members that the vehicles' performance and histories could tell us a lot about how the environments were affecting the structure, if we paid close attention to what we were seeing. The Panel began interrogating the historical problem reports in the aft of the vehicles to see if there were any other instances of structural cracking or tile failures that would illuminate the acoustic environment discussion. The Panel heard about several instances of tile failures, especially around the OMS pods and vertical tail.
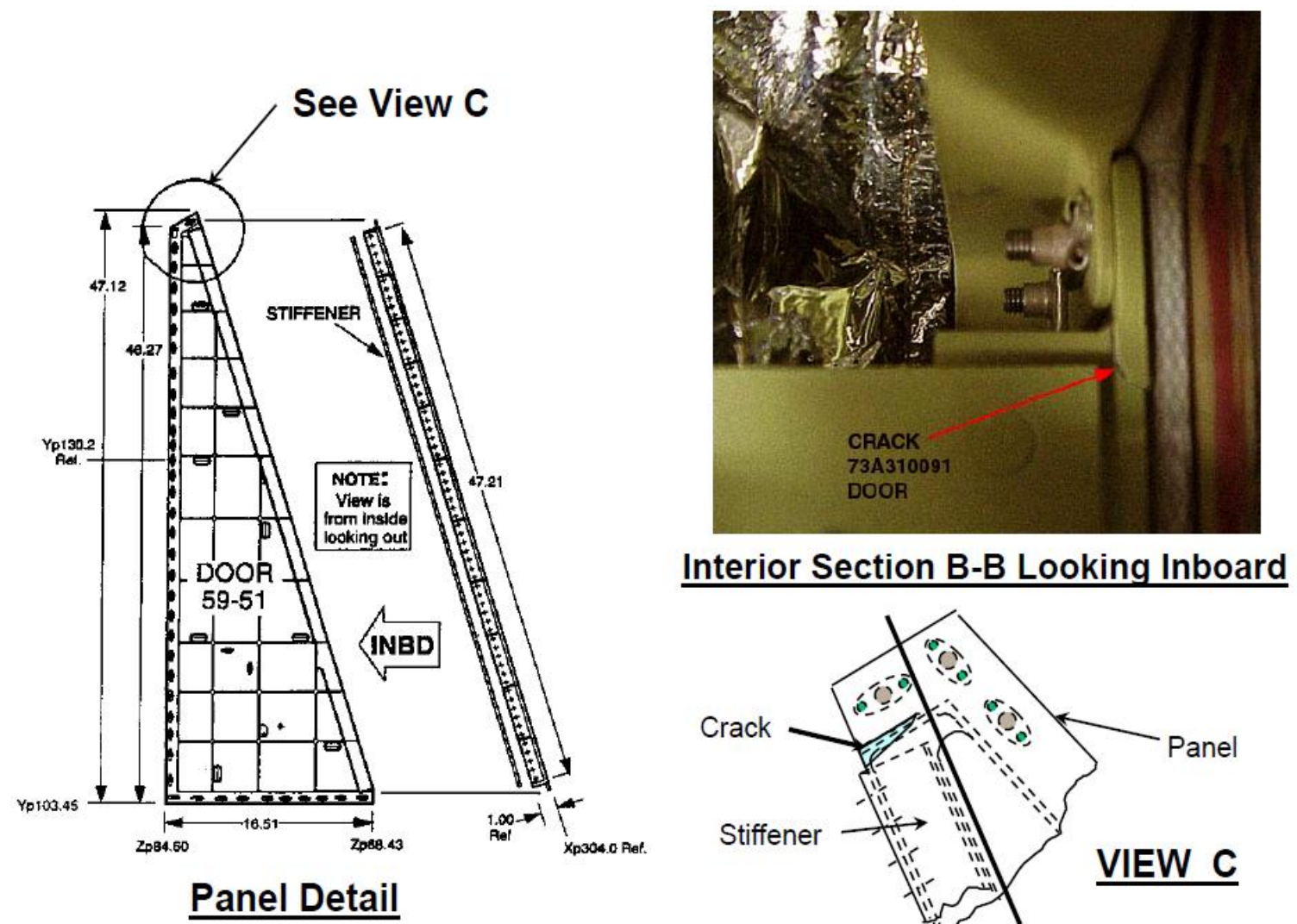

Figure 9. OV-102 OMS Pod Helium Access Door Crack.

The OMS RCS stinger attach point posed a serious challenge to the structures team and the Shuttle Program. The news that this primary structure component had potentially used up its structural life came in October 2009, right before the scheduled launch of STS-129 on OV-104. Because the difference between the predicted life (22 missions) and the required life (100) were significant, the Program faced a significant dilemma. The OMS Pod installed on OV-104 for this flight had already flown 41 times, so it was possible that the part would already be cracked. Conversely, there were conservatisms in the analysis that made the Program, structural engineers and loads analysts uncertain as to the magnitude of the risk. The major uncertainty was that the environment being applied to this part analytically was based on measurements taken at the center of the base heat shield. The part in question was in the OMS Pod, off in the corner of the aft end of the Orbiter (see Figure 10). Another major uncertainty was how the fatigue life was being calculated - Boeing had been forced to use previously published reports and scaled from those (the old dynamic models could not be used on our present-day computers). During the pre-flight reviews they were busy rebuilding the dynamic model to enable a more accurate stress prediction for this part and a more confident understanding of the issues at hand. 


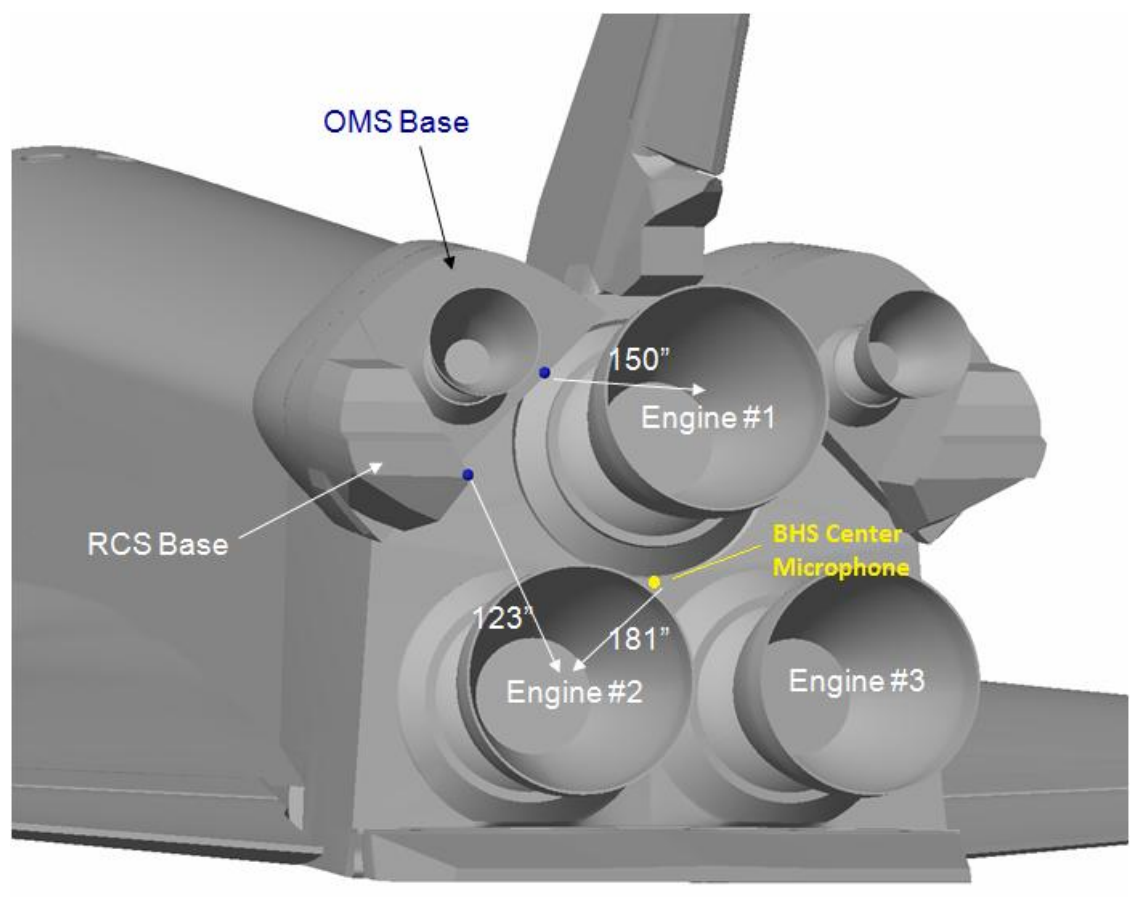

Figure 10. Base Heat Shield View.

The Orbiter Project had also managed to do a boroscope inspection of the RCS stinger attach fitting on another vehicle. This gave us some confidence that at least that part had not grossly cracked. By the time we got to the Agency flight readiness review on October 29, 2009, Orbiter Project had not yet completed their structural analysis. The Orbiter team had initiated a fatigue bench test program on a new stinger attach fitting, started work on installing an accelerometer to a panel inside the OV-104 RCS that would show a loads response like the fitting, and was working on their model, with an expected completion date of Nov. 11, 2009 - five days before launch. On Nov. 12, the Orbiter Project reported on the results of their work - updating the dynamic model showed that the fatigue life of the RCS stinger was greater than what was required. The Program Manager agreed with the technical teams' recommendations and STS-129 launched as scheduled four days later.

Instrumentation was ultimately added to the launch pad structure and the RCS stinger on OV-103 as well. These instruments provided data for the remainder of the Shuttle Program, and helped the Panel develop a very detailed understanding of the acoustic environment for this part of the vehicle. The environment applied to the OMS/RCS was revised from the center BHS environment to the BHS corner environment. A final update to the environment was made in 2011 and documented in an appendix to the Acoustics and Shock Data Book. See Figure 11 for an example of the final acoustic environment compared to the original design data book. 


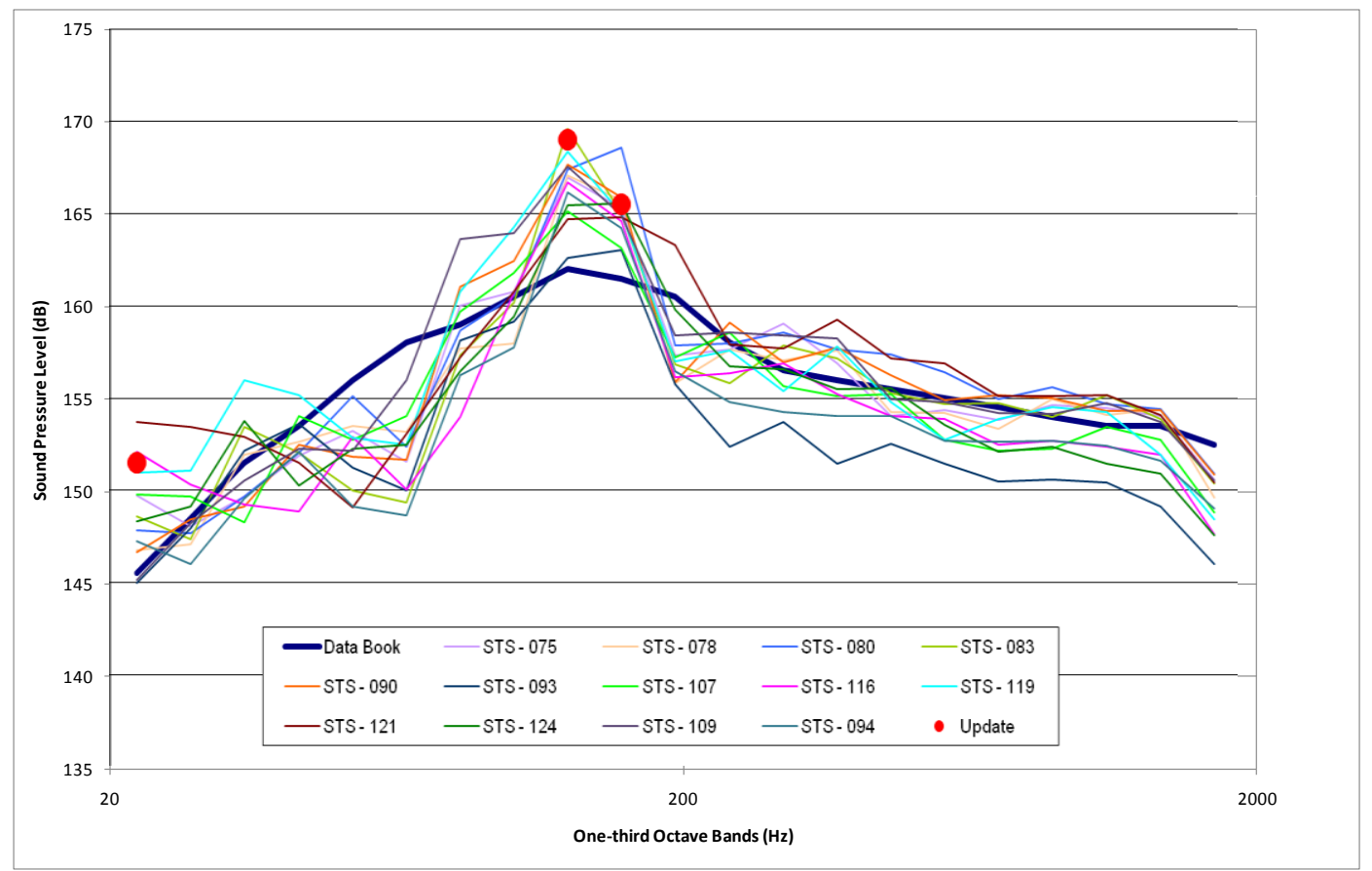

Figure 11. Final Environment Updates Compared to Original Data Book Limits at BHS Center.

\section{Conclusions}

The Shuttle Program Integrated Loads and Dynamics Panel provided valuable expertise over the duration of the Program. The Panel used as much engineering data as was available, and asked for more when necessary, to identify design environments at the beginning of the vehicle design process, verify the environments as the Shuttle started operations, and monitor performance and changes as the Program matured. While the leadership and composition of the Panel changed over the duration of the program, the quality of its expertise and the dedication of its members to safe and successful operation of the Shuttle were constant. The members of the Panel learned how to listen to the vehicle, and how to use the Program processes to insist on instrumentation, testing and validation work where the Panel felt it was necessary. Where errors were found in the Panel's products or the Program's operational decisions, the necessary expertise was available to provide support, information and corrective action. Equally important to the Panel's success were the partnerships that it developed with other Program technical panels, such as the Aero Loads Panel, the Thermal Panel and others.

\section{References}

\footnotetext{
${ }^{1}$ Glynn, P. C. and Moser, T. L. "Orbiter Structural Design and Verification,” Space Shuttle Program Technical Conference, Johnson Space Center, Houston, TX, 1986.

${ }^{2}$ Mackey, A. and Gatto, R., "Structural Load Challenges During Space Shuttle Development," Space Shuttle Program Technical Conference, Johnson Space Center, Houston, TX, 1986.

${ }^{3}$ Ryan, R. S., Jones, J. H., Guest, S. H., Struck, H. G., Rheifurth, M. H. and Verderaime, V. S., "Propulsion System Ignition Overpressure for the Space Shuttle," NASA Marshall Space Flight Center, NASA TM-82458, December 1981.

${ }^{4}$ Lai, S., "Development of Space Shuttle Ignition Overpressure Environment and Correlation with Flight Data," NASA Langley Research Center Shuttle Performance: Lessons Learned, Part 1 (SEE N84-10115 01-16); United States; 1983, p 259282.

${ }^{5}$ Sturber, T. E. and Stone, J. S., "Aerodynamic Analysis of the Loft Anomaly Observed on Orbital Flight Tests of the Space Shuttle," ibid., p 59-78.

${ }^{6}$ Dougherty, N. S. et. al., "Computational Fluid Dynamics Analysis of Space Shuttle Main Engine Multiple Plume Flows at High-altitude Flight Conditions," NASA Goddard Space Flight Center, Tenth Workshop for Computational Fluid Dynamic Applications in Rocket Propulsion, Part 2 (SEE N92-32245 23-34); UNITED STATES; 1992, p 923-943.
} 
7 Hawk, R.J., Sesto, L.D., and Rusch, F.W., "Acceleration Measurements on the Facilities Verification Vehicle (PATHFINDER) During Initial Rollout to Launch Pad”, Rockwell International North American Aircraft Division, SDD-79-29, August 2, 1979.

8 "MTI 61G Rollout Final Test Report", Morton Thiokol, Inc., TWR-16710, June 4, 1987.

9 "Integrated Test Requirements for Rollout Fatigue Loads Spectra Methodology Verification”, NASA Johnson Space Center, NSTS 60512, November 13, 2003.

10 James, G.J., Carne, T. G., and Wilson, B, "Reconstruction of the Space Shuttle Roll-out Forcing Function", 25 International Modal Analysis Conference, Orlando, FL, SEM, 2007. 


\title{
The Living Legacy: Integrated Loads for Shuttle
}

\section{Space Shuttle Program Integrated Loads \& Dynamics}

\author{
Presented By \\ Karen Bernstein
}

Shuttle Program Integrated Loads Panel

Co-Chair NASA/JSC ES2

27-29 September 2011 karen.s.bernstein@nasa.gov 


\section{Outline}

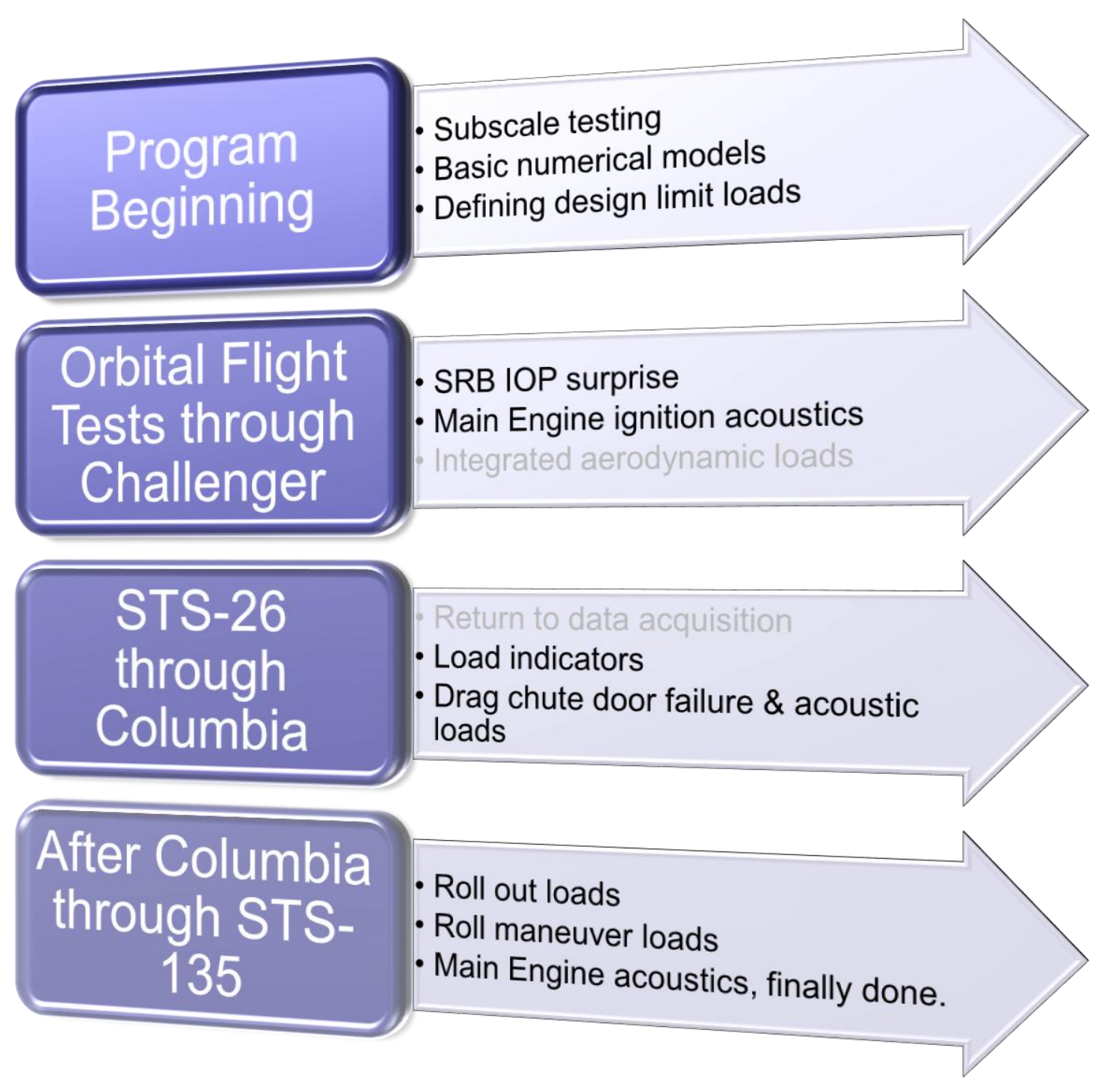




\section{STS-1}

First five missions were designated as Orbital Flight Tests (OFTs)

- Columbia vehicle was instrumented to develop flight test data

- Flight tests are meant to examine predictions vs. reality

- Launch on 4/12/81 had unexpected structures and loads issues

- Buckled a fwd RCS tank strut in Orbiter fuselage

- Ascent trajectory diverged from predictions

- Measured strain in Orbiter wings did not agree with predictions

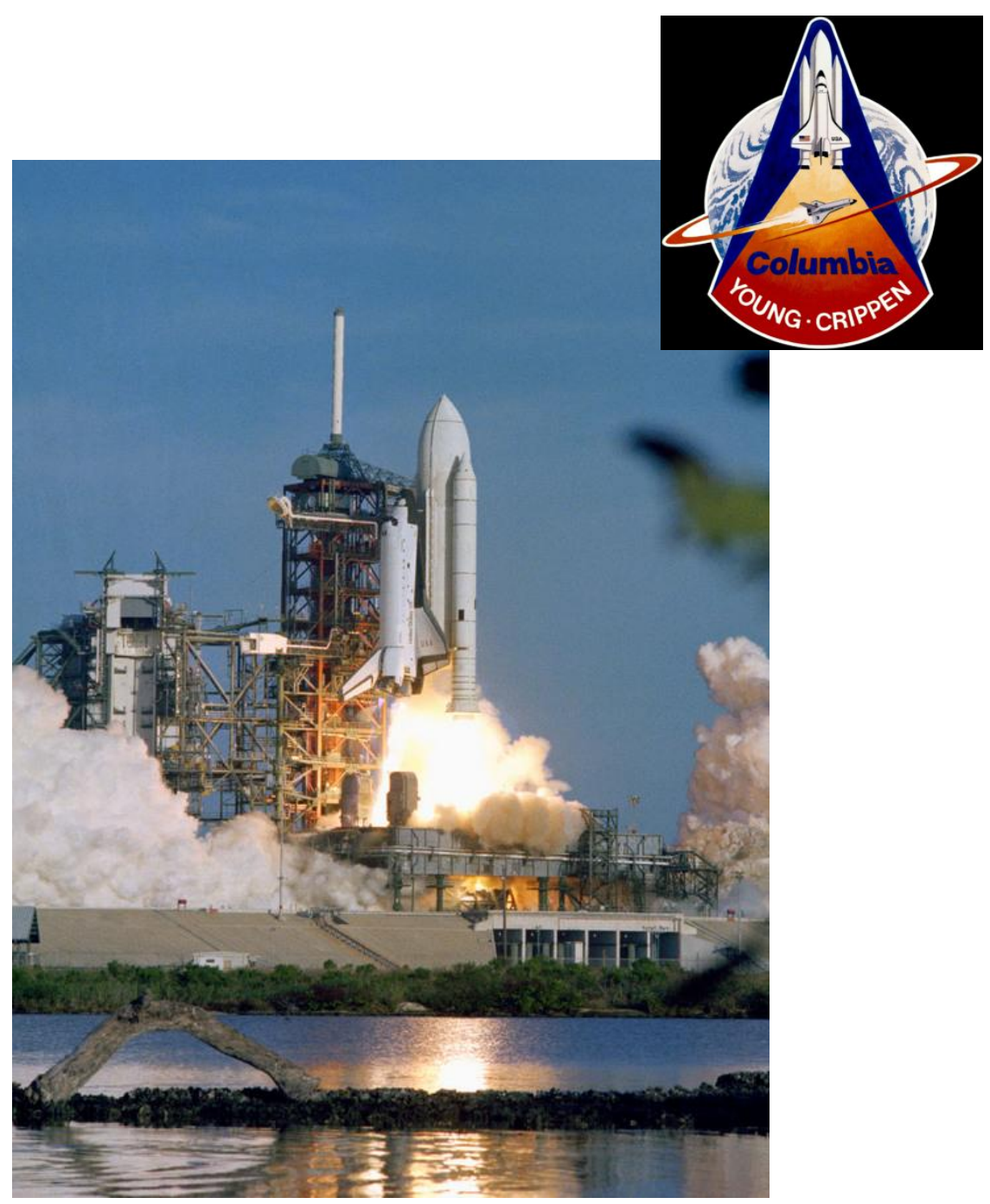




\section{SRB Ignition Overpressure}

- FWD RCS tank strut buckling was due to high loads from the SRB ignition overpressure wave

- Magnitude of pressure wave was reasonably close to predicted magnitude

- Frequency content of pressure wave was lower than predicted

- Vehicle response to pressure wave was higher than predicted

- Program announced STS-2 would not launch until risks from SRB IOP were adequately addressed

- Level II Loads Panel tasked with resolving loads, vehicle response

- Developed tiger team to focus on reducing the magnitude of the pressure wave

- Modification to MLP implemented within original schedule! 


\section{Retesting and Revising}

After STS-1, Program repeated the subscale testing using Tomahawk motors and a $6.4 \%$ model of the Orbiter

- Test reconfigured to eliminate time lag of motor ignition

- Retests identified true location of wave origin, which was about 40' away from pre-flight predictions

- Helped water deluge tiger team to come up with effective solutions

- Water deluge system modified to include water troughs and an increased deluge

- Cut temperature of exhaust plume, reduced magnitude of wave and lowered the frequency content of the wave

- Numerical analysis of full-scale Orbiter updated

- Analysis of test data revised to eliminate excessive smoothing

- Added modal content to model

- Better prediction of vehicle response to IOP

- STS-2 + subs IOP significantly lower than STS-1

- Lesson Learned: Ignition overpressure is a significant environment for the spacecraft structure, and should be fully examined before manned launches begin. 


\section{Main Engine Ignition Environment}

Subscale testing for SRB IOP did not provide SSME data for predicting MEI IOP or acoustics

- Liquid engine for this test program was too unlike SSME for valid data

- Main Propulsion System Test Articles were being constructed in this time frame

- Program intent was to use these flight quality SSMEs on a test stand to develop environments for launch

- MPTA finally happened in 1979; engineers used data to predict IOP and acoustics

- OFT missions demonstrated that predictions were significantly lower than actual environment

- Flight data taken with nine instruments distributed over the aft half of vehicle

- Large areas covered by single instruments

- Half-second window used in FFT analysis of acoustic data

- Following STS-5 the acoustic environment was documented in Loads Data Book

- Structural analysis of components and systems in vehicle aft demonstrated adequate strength and life 


\section{Center of Base Heatshield MEl acoustics}

- Data placed into $1 / 3$ octave bands

- Processed using 0.5 second Hanning window

- Limits drawn to envelope maximum data points

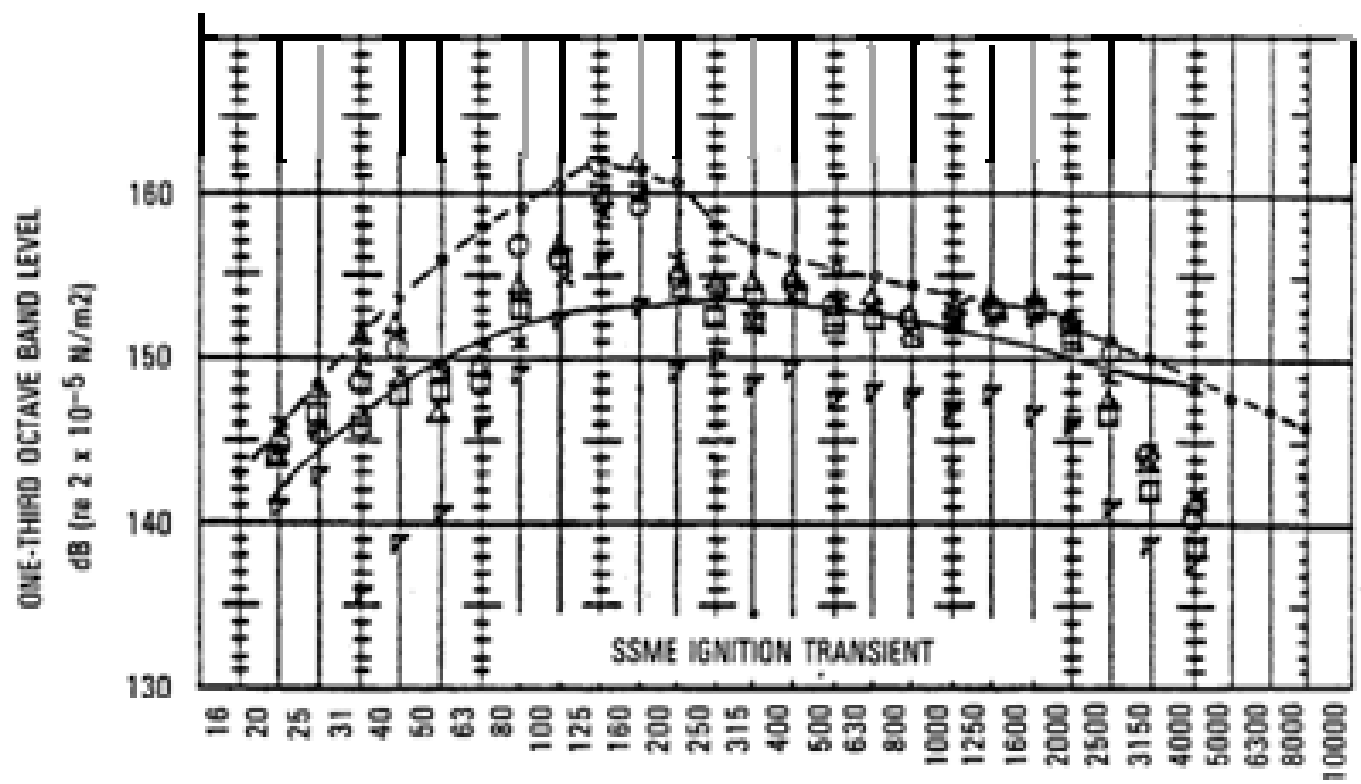

ONE-THIRO OCTAVE BAND CENTER FAEOUENCIES-HERTZ

TEST PREDICTED ZONAL DESIGN LIMIT — FUGHT DATA: TEST PREDICTED ZONAL NOMINAL FLIGHT DERIVED ZONAL
STS-1 0000 STS-4 DOD STS $-2 \times \times \times \times$ STS $-5 \nabla \nabla \nabla \nabla$ STS-3 $\Delta \Delta \Delta \Delta$

MEASUREMENT: VOBY9686A,

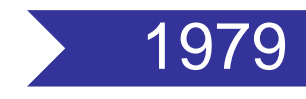


Level II - the Space Shuttle Program Office and its supporting engineers - simulates ground/flight regimes to predict integrated vehicle loads

- Rollout, Prelaunch, Liftoff, \& Ascent

- Simulations consist of many load cases with many time steps

- Only critical cases and time steps for the requested data need to be delivered to the projects

- Complete time history ended up being delivered so projects could pull additional data as needed

- More recently, time history was not delivered, but data storage methods are much different in this century than last

- We needed a tool to search each load case to find the critical time slice

- Thus ... load indicators

- Load Indicators were defined prior to STS-1, but not all structural components were using them 


\section{Load Indicators}

Each project identifies critical locations for their hardware

- The project determines the simulation data required to analyze the critical locations

- The project creates an equation, or indicator, for finding the data that will maximize or minimize the analysis at a critical location

- Load indicators are based on structural tests and analyses

- Load or combination of loads

- Acceleration

- Stress

- Displacement

- Load indicator limits reflect the maximum value that ensures the factor of safety is protected 


\section{SRB Aft Skirt Weld Failure}

- SRB Aft Skirts support the entire Shuttle stack on the Mobile Launch Platform prior to liftoff

- Stacking in Vehicle Assembly Building

- Rollout to launch pad on Crawler

- Orbiter main engine build-up prior to SRB ignition

- Aft Skirt is a welded aluminum conical structure

- Attaches to launch pad at four support points

- Hold-down studs with frangible nuts restrain stack until SRB ignition

- Structural tests identified the forging-to-skin weld as the most critical location on the aft skirt

- This weld failed during a qualification test in 1986 


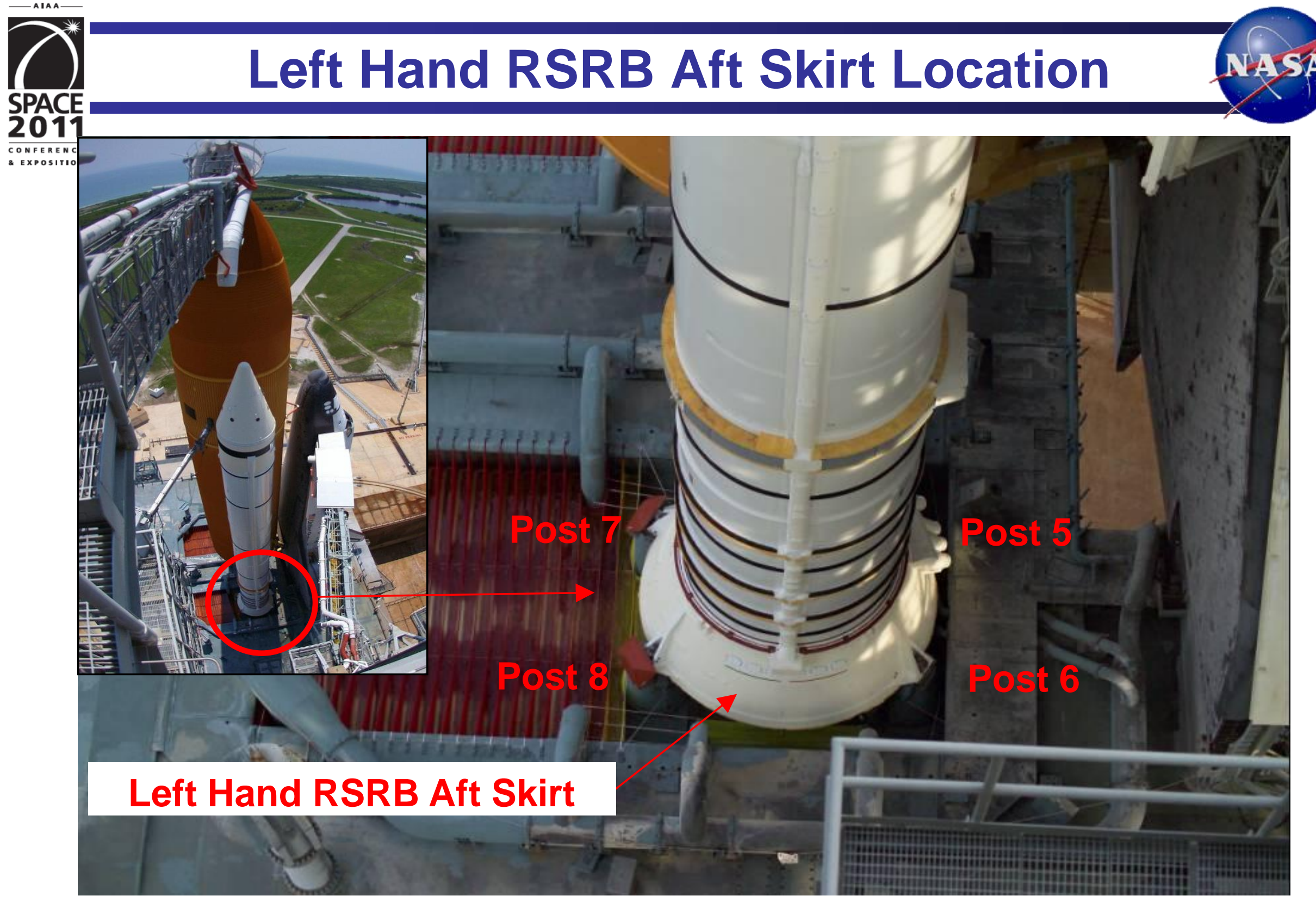

\section{SPACE 201 CONFERENC} \& Expositio

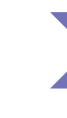

$1979>1986$ $1999>2003>2006>2009$ 


\section{Aft Skirt Structural Test Failure}

load

- During a structural qualification test for a new composite motorcase

- The aft skirt was part of the test fixture

- Qual test load cases were the maximum axial compression and tension load at each hold-down post

- Maximum axial

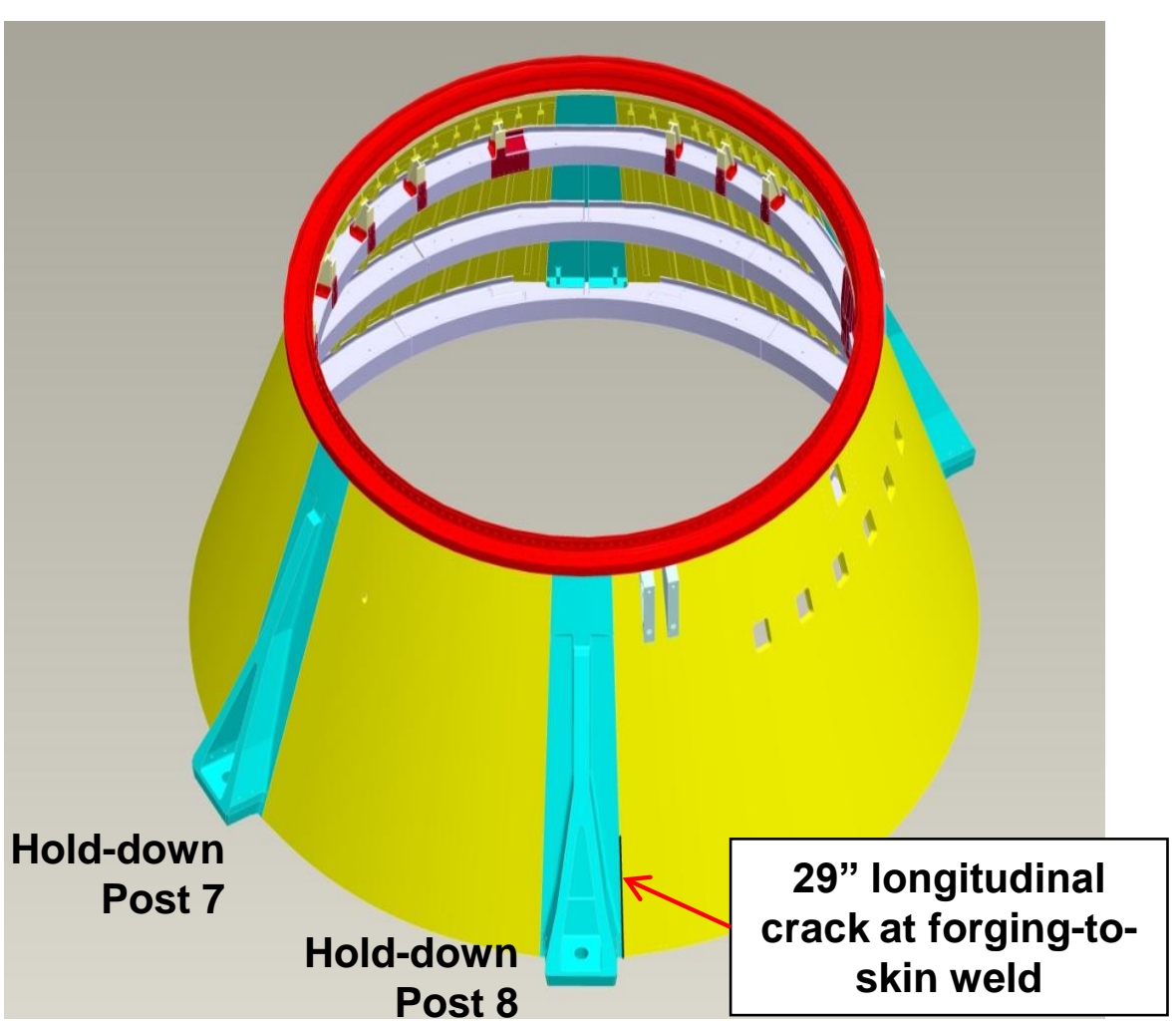
compression for this test was approximately the same as in previous SRB qual tests

( -1440 kips vs -1430 kips) 


\section{Aft Skirt Structural Tests}

A third structural test was conducted in 1988

- Tested structural modification designed to strengthen weld

- Weld again failed at $129 \%$ of design load

- Maximum axial compression load only 1294 kips

- After STA-3, an equation relating the weld stress to the radial, tangential, and axial footpad loads at each of the 4 footpads was developed using influence coefficients from test data and finite element models

\begin{tabular}{|c|c|c|c|c|}
\hline \multicolumn{5}{|c|}{ STA-1 @ 100\% Load } \\
\hline \multirow{5}{*}{ Fx } & POST 5 & POST 6 & POST 7 & POST 8 \\
\cline { 2 - 5 } Fr & 575.4 & 637.1 & -1435.7 & -1296.4 \\
Ft & 52.1 & 40.7 & -403.6 & -361.4 \\
\cline { 2 - 5 } CWSI & -195 & 285.7 & -181.4 & 251.4 \\
\cline { 2 - 5 } & $\mathbf{- 5 1}$ & $\mathbf{- 6 8 . 5}$ & $\mathbf{5 1 . 9}$ & $\mathbf{5 1 . 9}$ \\
\hline
\end{tabular}

- The Critical Weld Stress Indicator equation calculates the stress in the aft skirt forging to skin weld using all 12 footpad loads as input

- $\quad$ This indicator had a value of 62.5 ksi for STA-3, 20\% higher than STA-1, showing why the weld failed at a lower compression load

\begin{tabular}{|c|c|c|c|c|}
\hline \multicolumn{5}{|c|}{ STA-2B @ 100\% Load } \\
\hline \multirow{5}{*}{ FX } & POST 5 & POST 6 & POST 7 & POST 8 \\
\cline { 2 - 5 } Fr & 569.8 & 579.1 & -1395.3 & -1440.3 \\
Ft & 30.2 & 92.3 & -320.9 & -312.4 \\
CWSI & -215.5 & 314.7 & -87.6 & 154.3 \\
\cline { 2 - 5 } & $\mathbf{- 6 0 . 6}$ & $\mathbf{- 4 9 . 9}$ & $\mathbf{5 5 . 6}$ & $\mathbf{6 8 . 5}$ \\
\hline
\end{tabular}

\begin{tabular}{|cc|c|c|c|}
\hline \multicolumn{5}{c}{ STA-3 @ 100\% Load } \\
\multirow{4}{*}{ Fx } & POST 5 & POST 6 & \multicolumn{1}{c|}{ POST 7 } & POST 8 \\
\cline { 2 - 5 } Fr & 457.1 & 602.1 & -1456.6 & -1294 \\
Ft & -11.7 & 39.2 & -351.7 & -283.4 \\
CWSI & -136.5 & 225.1 & -140.6 & 164.1 \\
\cline { 2 - 5 } & $\mathbf{- 4 8 . 8}$ & $\mathbf{- 5 8}$ & $\mathbf{6 0 . 9}$ & $\mathbf{6 2 . 5}$ \\
\hline
\end{tabular}




\section{Load Indicators}

- Lesson learned was that the stress in the critical weld is a function of all forces at each of the four hold-down posts

- Not just maximum or minimum axial load at a single post

- Load indicators are also an important tool to set maximum allowable limits to protect certification during future load cycles

- The CWSI was used for several years to protect the weld until a new modification was implemented

- Lesson Learned: Accurate and comprehensive load indicators are needed for Level II to provide loads that maximize the stress in critical locations 


\section{Drag Chute Door Failure}

Shuttle Program decided to renew data collection from instrumented vehicles after Challenger

- Main Engine ignition acoustics exceeded data book values

- Not a significant risk driver from Program's point of view in 1988

- In October 1998, the Orbiter Drag Chute Door fell off the vehicle during launch of STS-95

- Attach pins failed due to overload, not fatigue

- What was the source of the overload? Tiger team considered

- Door response to acoustics higher than expected

- Environment was not specified correctly

- Local hydrogen detonation overloaded door

- Immediate resolution

- Replace aluminum pins with Inconel

- Add instrumentation to new door to measure environment \& response directly

- Conclusive evidence of acoustic environment exceeding data book limits was found by this instrument

- Level II Loads Panel began a new examination of MEl acoustics, MEI IOP and SRB IOP

- Work on these environments was still on-going when Columbia accident redirected our focus in 2003.

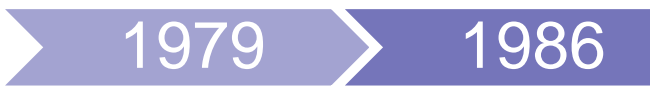

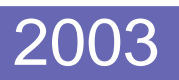




\section{Roll-out Loads Chronology}

Roll-out from VAB to pad takes many hours

- Crawler holds entire stack and mobile launch pad

- In 1979 a roll-out test found the loads to be benign

- Revisited in 1986 to examine SRB strains post-Challenger

- No revision to environments were made

- Extreme weather situations in Florida led to discussions of roll-out speeds and variances in loads

- MLP was instrumented 1999

- Data then used in fatigue analysis that provided results in 2003

- Yikes! Some Orbiter components had low fatigue life according to analysis

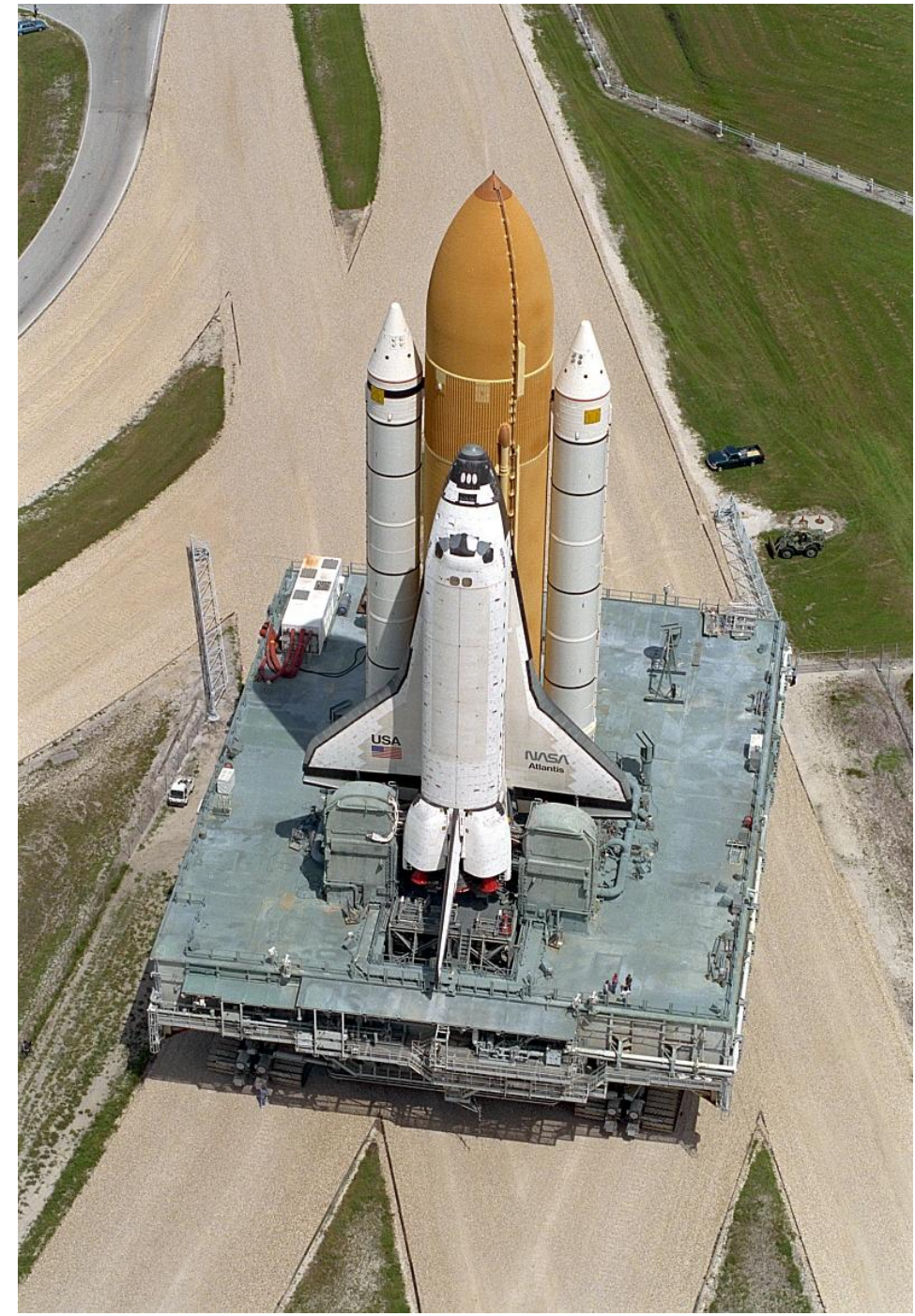




\section{Roll-Out Loads Finalized \& Controlled}

In November 2003, NASA conducted a "partial stack test"

- A pair of SRBs and an ET crossbeam were rolled to obtain operating data at various speeds and surface conditions

- "Partial stack" accounted for $97 \%$ of full Shuttle stack mass

- "Partial stack" did not include all of the system dynamics

- Test demonstrated that the roll-out forcing function contains a rich spectrum with multiple narrow band excitation forces

- Individual modes of the vehicle can be driven into resonance

- Vehicle response could be much higher than previously predicted

- In 2005 the MLP and crawler were instrumented and tested without the stack

- In 2006 the STS-115 stack was rolled to the pad with a full suite of instruments on the Orbiter, SRBs, MLP and crawler.

- Data was used to generate forcing function estimates to better predict Shuttle vehicle fatigue

- Final analysis delivered in spring 2009

- Shuttle vehicle fatigue life was within requirements

- Crawler speeds were limited to 0.8 to $0.9 \mathrm{mph}$ to avoid higher loads at $1 \mathrm{mph}$ and above

- Lesson learned: Examine loading events throughout a system's life cycle to find critical loads for strength and fatigue 


\section{Certification of the Roll Maneuver}

- Shuttle stack rolls during ascent from launch attitude to the proper orientation for the final orbital inclination

- Maneuver occurs at very slow velocities (Mach 0.2 to 0.5); resulting loads are intuitively low

- Initial integrated loads analyses did not include an evaluation of these loads

- After the STS-107 accident, vehicle loads for the entire ascent were reconstructed

- Results showed that the SRB aft interface load was exceeding a certification redline for the Lightweight ET configuration

- Lightweight ET configuration would not be flown again, but...

- STS-107 reconstructed loads were within $5 \%$ of the certified limit load for the new integrated vehicle

- Roll maneuver needed further assessment

$1979>1986$ 


\section{Analysis Plan and Conclusions}

Pitch gimballing of the SRB motors put a large up and down

(Z) load on the SRB

- This is reacted by the aft attach struts between the SRB and the ET.

- Strut loading led to an evaluation of other Shuttle elements' reactions

- Orbiter (wings, vertical tail) sensitive to roll maneuver combined with winds and aero loads

- Multi-year effort kicked off to fully understand highly integrated loading event

- $\quad$ Late in 2003, the loads community developed an analysis plan

- examined previous flight data (STS-26, -27, and -29 had instrumented struts)

- determined wind variations in this flight regime

- developed an understanding of the deficiencies in the aerodynamics database.

- In 2004 team broadened to include Aero Panel; the

Guidance, Navigation, and Control (GNC) Panel; the Natural Environments Panel; and the Day of Launch (DOL) community

- Conclusions of this study

- SRB roll maneuver loads not sensitive to winds

- Orbiter roll maneuver loads ARE sensitive to winds

- Performance enhancement for ISS missions increased strut loads

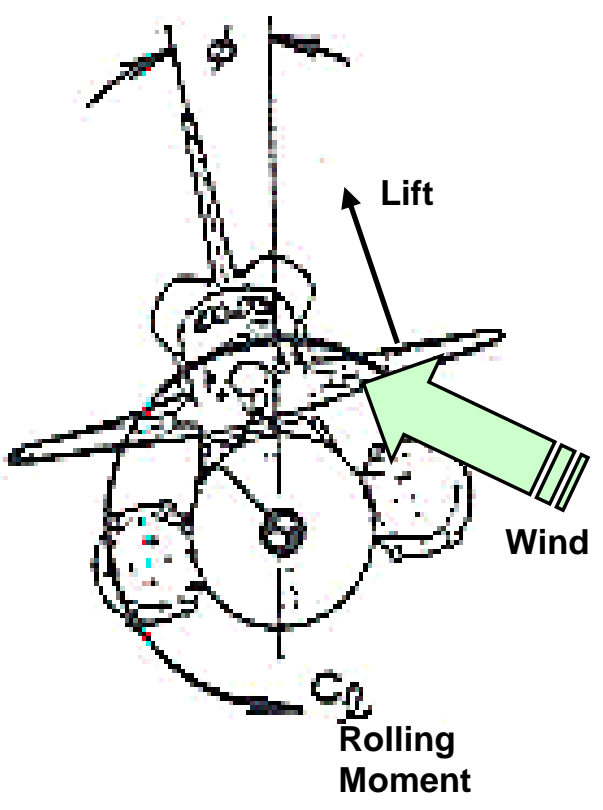

\section{The Shuttle Program decided that Roll Maneuver needed a full certification analysis}

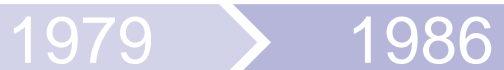

\section{3}


Roll Maneuver Results:

Sample Wing Root Mx Time History from 2004 Study

January Dispersed Left Wing Root Moment (Mx) 150 Wind Envelopes

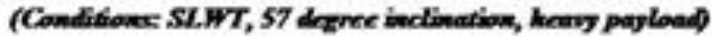

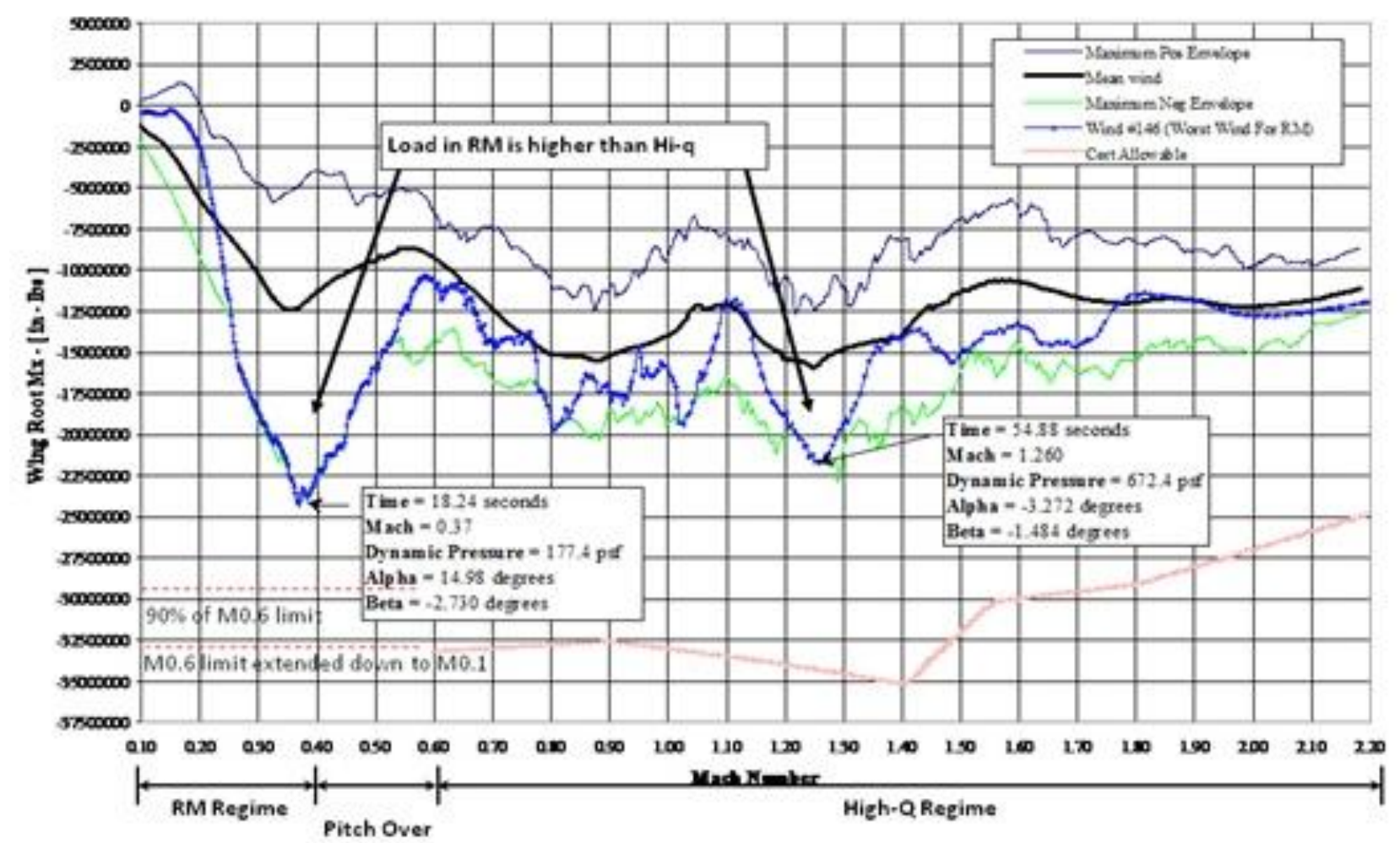

Example of an Orbiter structural load peaking during Roll Maneuver, an unexpected discovery 25 years into the operation of the Shuttle Program. 
- Wind-tunnel data and CFD results did not agree for $\alpha=19^{\circ}$ (beyond stall)

- Team's work relied on this new CFD-based Roll Maneuver Aerodynamics Database (called RMAD)

- Team decided to replace the CFD-based Orbiter aerodynamic loads in RMAD with data from a recent wind tunnel test (denoted as IA-700)

- $\quad$ STS-114 mission support required team's attention, so Program proceeded with RMAD \& known errors

- Operational constraints imposed to waive launch if the winds would cause an Orbiter angle-ofattack of greater than $19^{\circ}$ during Roll Maneuver.

- Besides the winds constraint, other issues worked by this team in 2005 and early 2006 included

- Development of Roll Maneuver Q-Planes (a set of trajectory constraint planes to protect structural limits)

- New wind persistence approach for RM

- Uncertainties for RMAD

- Day-of-Launch constraints implementation

- Transition aerodynamics (pad to start of Roll maneuver region)

- Balanced load cases for all elements including cargo

- Launch probability

- Fatigue life ground rules

- Coverage of engine-out cases

- Wing buffet loads

- Component loads (Orbiter windows, ET/Orbiter interface mechanisms, payload bay cameras, etc.)

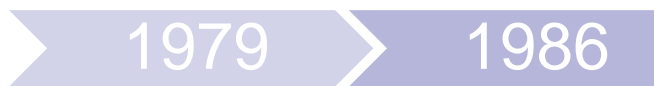




\section{Final Definition of RMAD in 2009}

Community rolled out RMAD2 in 2006, using the IA-700 wind tunnel data to address the 19 degree discrepancy

- Buffet increment updated based on the IA-700 wind tunnel data

- New buffet loads were higher

- New problem surfaced: decades-old discrepancy was found in the ascent loads codes

- Input coordinate that defines the aft SRB/ET separation plane was not defined correctly in some codes

- Updating the coordinate generated additional load indicator exceedances in the SRB and the ET

- STS-117 and STS-118 were flown with the incorrect coordinates driving some of the calculations for a limited number of indicators

- Balanced load cases to generically clear these exceedances were put off for some time as code updates and re-runs had to be performed

- In the end the community accepted RMAD2 with higher loads past wing stall (the $19^{\circ}$ boundary)

- $\quad$ STS-125 (Hubble) and STS-127 (ISS) in mid 2009 were the first missions to fly with no outstanding Roll Maneuver issues.

- Lesson Learned: Any maneuver a launch vehicle executes during its ascent should be evaluated and included in the limit load and fatigue load set for design assessment, especially after operational or configuration changes.

- Original designers downplayed the Roll Maneuver loads to focus on higher-energy events

- As the Program unfolded the community should have monitored the lower level events (such as Roll Maneuver)

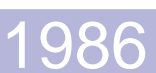

\section{9} AIAA Space 2011 - September 27-29, 2011 


\section{Main Engine Ignition Acoustics, $3^{\text {rd }}$ Try}

\section{Recap:}

- 1980 definition of MEl acoustics was shown wrong by OFT

- OFT data book entry was demonstrated wrong by drag chute door failure in 1998

- STS-107 accident analysis required reconstruction of all loads, including launch overpressure and acoustics

- Could these environments have caused structural damage resulting in Columbia's failure during reentry?

- Loads panel noted typical design environment exceedances, but did not find root cause of Columbia's accident in launch acoustics or overpressure

- Loads Panel initiated a review of acoustic and pressure data methodology

- FFT Window duration was changed from 0.5 seconds to 2 seconds

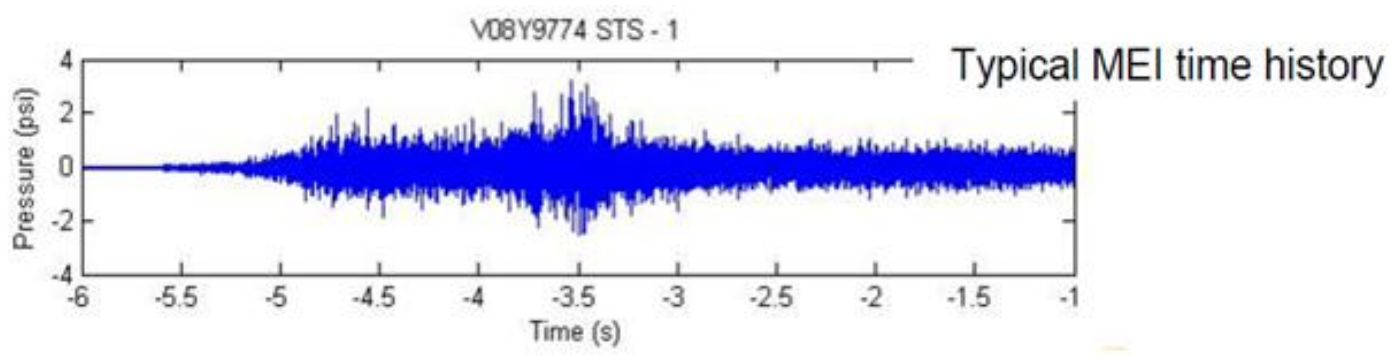

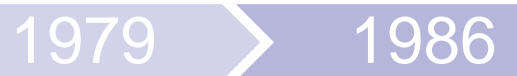




\section{More Data Acquired}

Loads panel requested new and reactivated instrumentation on Orbiter vehicles

- Approved in late 2004

- Took 20 months to implement

- New data brought new questions

- Acoustic exceedances due to Main Engine Block Update? Engine experts examined this question and reported no correlation found.

- Did the change in window duration make sense?

- Fatigue analysis did not change

- Comparing measurements to early data was difficult

- Longer duration window blunted environment extremes

- Orbiter analysts asked to assess fatigue response using both windows

- 2008 results showed some items at risk for failure

- Accelerometer data from Orbiter also demonstrated that some structures responded to very short duration acoustic energy

- Loads Panel members questioned the validity of the acoustic data

- Several instruments had failed in service and been replaced

- Instruments had never been calibrated after installation

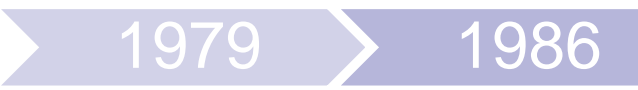

2009

2011 


\section{Recalibration \& New Ground Rules}

To make engineering decisions, analysts need calibrated instruments

- The Program agreed and implemented an effort to recalibrate every available pressure sensor and microphone

- This took more than a year

- Work was dependent on the vehicle launch processing flow

- Calibration equipment had to be borrowed from another center

- Loads Panel agreed to a set of ground rules to determine when the design loads data book acoustic limits would be updated

- RMS of the pressure time history with a 0.05 second step and a 0.5 second window to find the highest value window for final processing, then two $4 \mathrm{~Hz}$ bandwidth fast Fourier transforms with no overlap to create a power spectrum.

- Convert power spectra into 1/3 octave decibels bands from 20 to $2000 \mathrm{~Hz}$.

- Decibel level for any frequency would be increased in the design limit if

- new environment exceeds previous design limit by more than $3 \mathrm{~dB}$ within one of the $1 / 3$ octave bins

- is not a singular deviation

- The delta $\mathrm{dB}$ for the increase is rounded to the nearest integer.

- Existing design limit data above post-flight data will not be lowered.

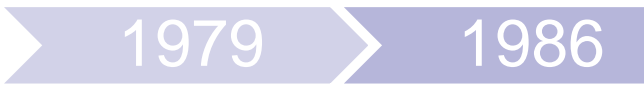

2009

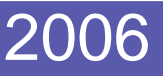

AIAA Space 2011 - September 27-29, 2011
2011 


\section{Data Analysis Following Recalibration}

Source of the peak MEI acoustics determined by correlating the acoustic data with MSFC analysis of the main engine ignition, including unsteady CFD

- Separation of the lip restricted shock

- Oscillation of the SSME nozzle during the start transient due to shock

- Panel could now understand

- How the environment was being measured

- How placement of the instruments (and vehicle components) could result in shadowing from certain parts of the acoustic environment

- Important when determining how to apply data from a few instruments to large structural areas of the vehicle being assessed

- In October 2009, the Orbiter Project structures team finished their analysis of the updated SSME IOP and MEl environments

- Included increases in sound pressure levels for

- Base heat shield (BHS) and Orbital Maneuvering System (OMS) Reaction Control System (RCS)

- Vertical tail and inboard elevon

- Body flap and upper fuselage aft of $X_{\circ} 940$.

- Two low life parts identified, tiles needed to be modified

- OMS RCS stinger attach point

- Access panel on OMS RCS

- several tiles on the RCS that needed minor modifications to maintain a positive margin of safety for strength.

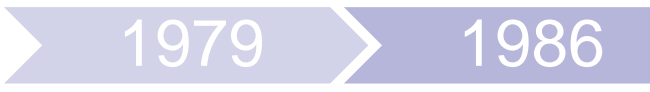

2011 


\section{What can happen to a structure from acoustic loads}

Orbiter Project structural engineers recalled that an OMS RCS access panel had cracked during Shuttle operations in the '90s, which was discovered in 2000 during a maintenance down-time for OV102. Following this problem report, all of the access doors on each vehicle were modified to strengthen this corner flange. During that rework, no other damaged doors were found and an assumed preexisting flaw on the OV-102 door was identified as the probable root cause of the crack.
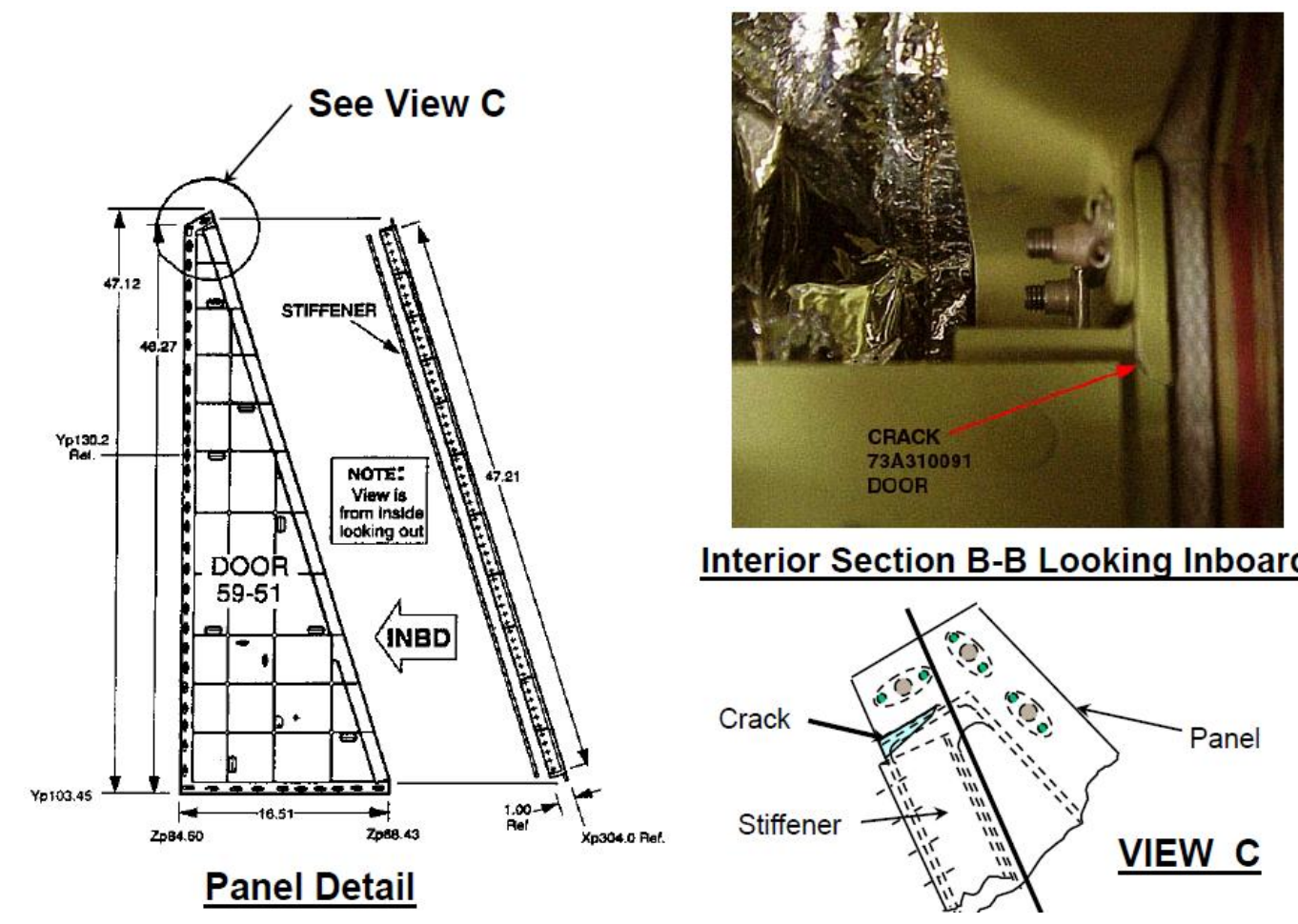

In hindsight, this crack might have been due to the acoustic environment.

In 2009 the Loads Panel searched problem reports for other instances of fatigue failures or tile problems in the Orbiter aft end. No significant patterns were found, although there were several instances of tiles falling off aft end at MEI.

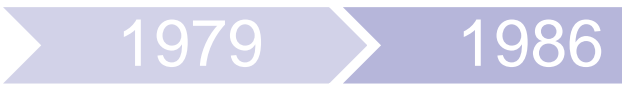

\section{9}

\section{9}




\section{OMS RCS Stinger Fatigue Life Problem}

Right before STS-129, Boeing reported that OMS RCS stinger attach point had an issue with new environment

- Predicted life $=22$ missions

- Required life =100 50 missions

- $\quad$ OMS Pod for STS-129 had already flown 41 times - possible that the part would already be cracked

- Conservatisms in the analysis led to uncertainties in magnitude of the risk

- Applied environment based on measurements taken at the center of the base heat shield.

- RCS Stinger was off in the corner of the aft end of the Orbiter

- Fatigue life calculations scaled from old dynamic models which could not be used on our present-day computers

- Boeing analysts worked the problem during the preflight review period

- Started a fatigue bench test program on a new piece part to correlate analysis results

- Installed an accelerometer to a panel inside the OV-104 RCS to measure structural response to acoustics

- Creating a new dynamics \& stress model for structure and fitting

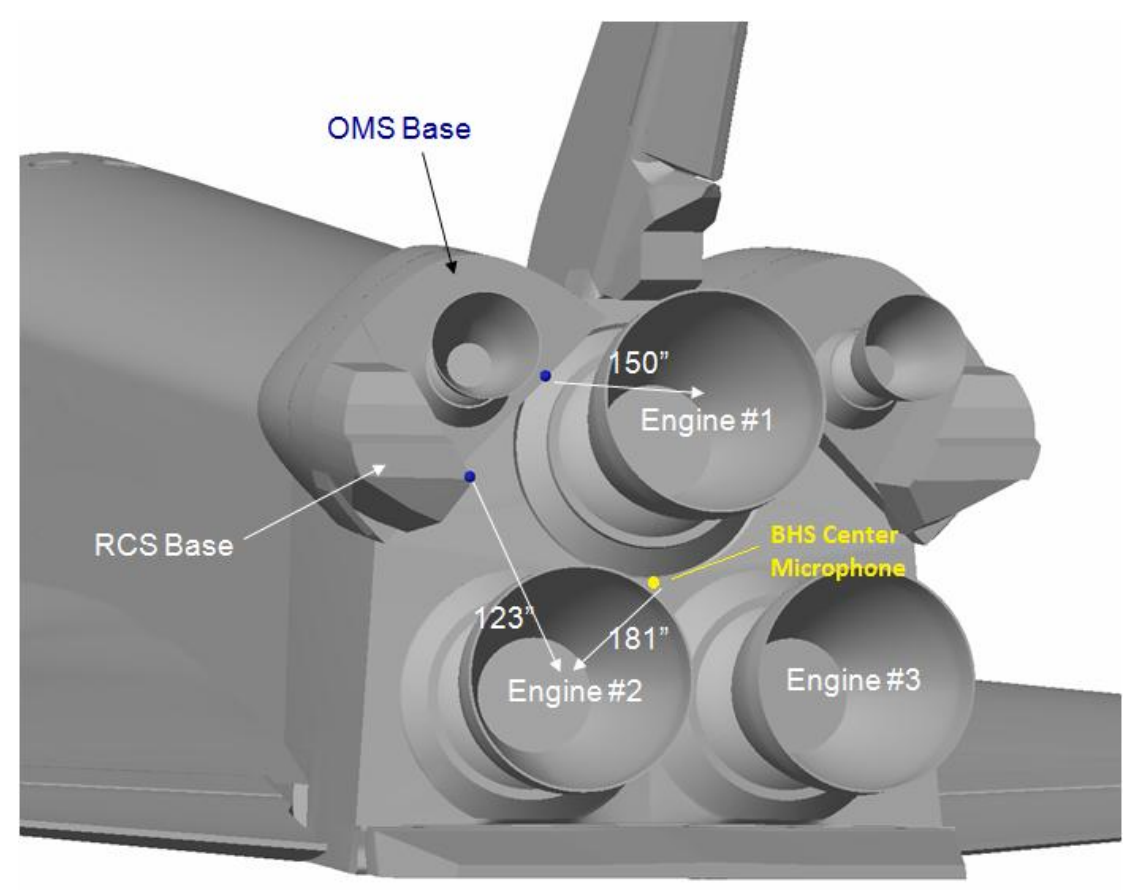

Four days before launch of STS129, Boeing reported that predicted fatigue life exceeded Program requirements

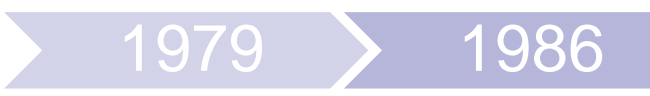

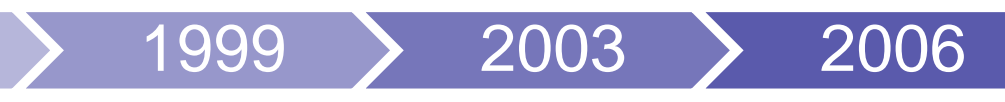

AIAA Space 2011 - September 27-29, 2011
2009

2011

AlAASpace $2017-S$ eptemiber 2 - 29,2011




\section{MEI Environment, Finally Updated}

2011 Update of MEI Acoustics Design Limits

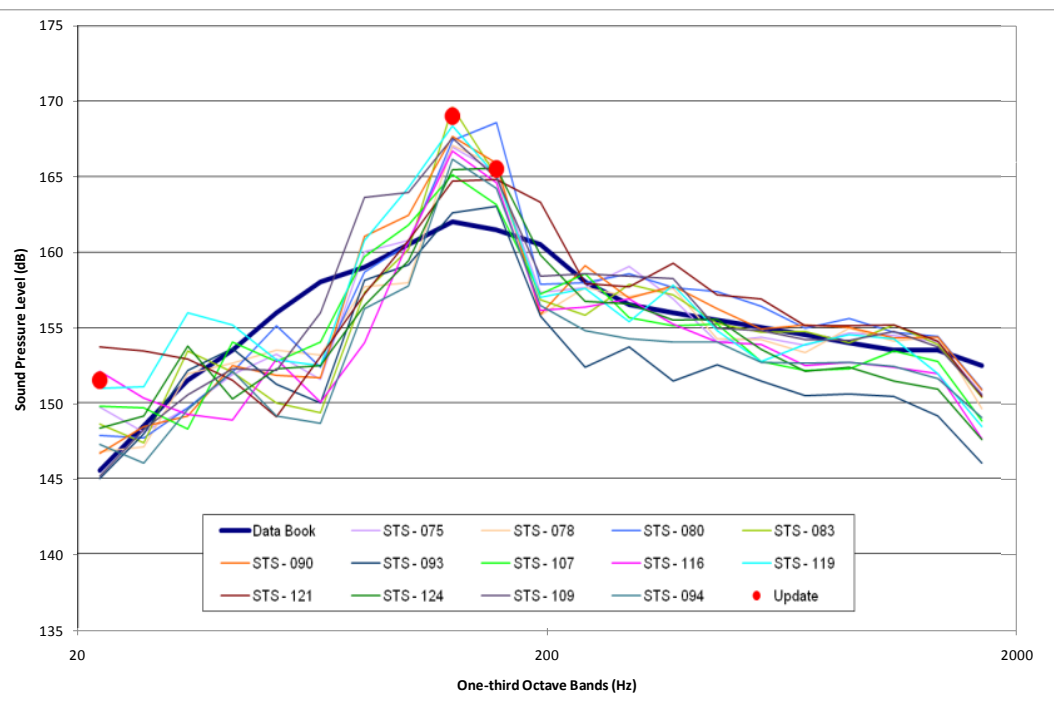

Lessons Learned - calibrate instruments used in engineering assessments, pay attention to data that deviates from expectations

Original Data Book, after OFT

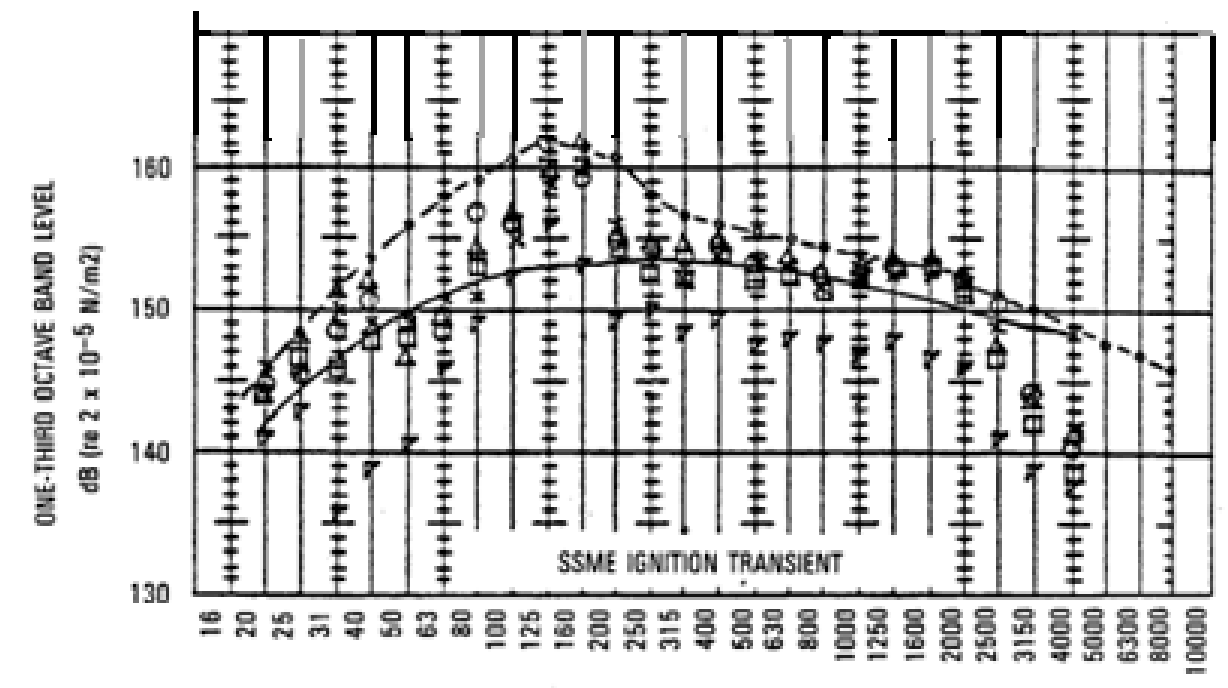

ONE-THIRO OCTAVE BAND CENTER FAEOUENCIES-HERTZ

TEST PREDICTED ZONAL DESIGN LIMIT — FUGHT DATA:

TEST PREDICTED ZONAL NOMINAL

FLIGHT DERIVED ZONAL

$----$ $\cdot-\cdot-$
STS-1 0000 STS-4 DOD STS $2 \times \times \times \times$ STS- $5 \nabla \nabla \nabla \nabla$ STS-3 $\Delta \Delta \Delta \Delta$ MEASUREMENT: VOBY9686A. 


\section{Conclusions}

Integrated Loads and Dynamics Panel existed from beginning to end of the Shuttle Program

- Identified design environments at the beginning of the integrated vehicle design process

- Verified the environments as the Shuttle started operations

- Monitored performance and changes as the Program matured

- Panel learned how to listen to the vehicle

- Panel learned how to use the Program processes to insist on instrumentation, testing and validation work where necessary

- Where errors were found in the Panel's products or the Program's operational decisions, the necessary expertise was available to provide support, information and corrective action

- Leadership and composition of the Panel changed over the duration of the program

- Interpanel relationships became more important as Program matured

- Quality of its expertise and the dedication of its members to safe and successful operation of the Shuttle were constant 